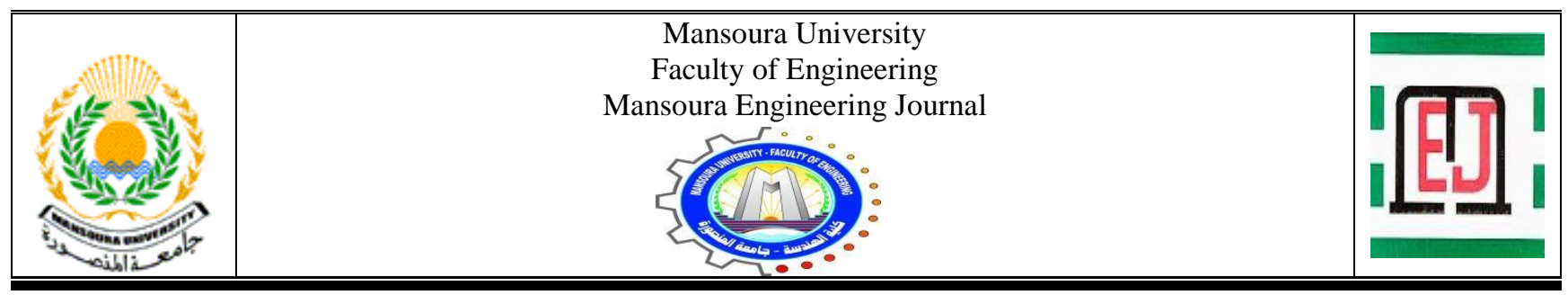

\title{
Comparative Analytical Study on Water Efficiency Category in Green Building Rating Systems
}

\author{
Raghda Abdelwahab Osman*, Sherif Ahmed Sheta and Heba Mohamed Abdou
}

\begin{tabular}{|l|}
\hline KEYWORDS: \\
Water efficiency, water \\
consumption,GPRS2018,LEED \\
BD\&C V4.1,GREEN STAR \\
design\& as built v1.3, Green \\
Building Rating Systems \\
,Buildings life cycle, rain water \\
,gray water,black water \\
\\
\end{tabular}

Abstract-Fresh water is a scarce resource that is slowly renewable, so water management is very important to achieve the sustainability of architecture and urbanization through the medium and long term. Recently, environmental assessment systems have been given attention and development by many countries globally and regionally, and thus assessment systems have spread to help the architect achieve a sustainable environment and implementing green building practices. This can be implemented by adopting each system strategies such as energy, water, materials...etc. Since the scarcity of fresh water is a global issue, this paper aims to identify clear strategies of water efficiency and how to preserve it to obtain the best strategies that can be used to improve water efficiency inside buildings in Egypt. To attain this aim, The study follows a clear theoretical methodology in which the issue of water is recognized globally and its impact on architecture as well as water efficiency during the life cycle of the building. Then, a comparative analytical study was conducted for water efficiency between the local GPRS 2018 assessment system against the two global assessment systems LEED BD\&CV1.4 and Green Star design \& as built V1.3. The study concluded with an applied example by applying the strategies of water efficiency in GPRS2018, to clarify strengths and weaknesses points.

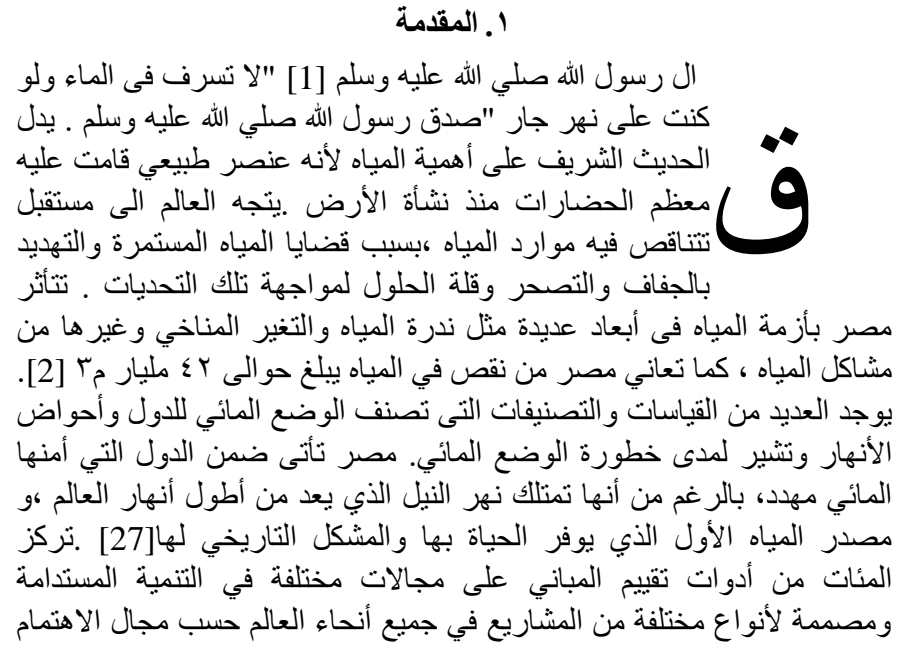

Received: (26 August, 2021) - Revised: (09 October, 2021) - Accepted: (04 November, 2021)

*Corresponding Author: Raghda Abdelwahab Osman Hamed Darwish,Researcher at architectural Engineering Dept., Faculty of Engineering, Mansoura University (masterdegree2022@ gmail.com)

Assoc. Prof. Sherif Ahmed Ali Sheta, Associate Professor-Architectural Engineering Department- Faculty of Engineering- Mansoura University ( sherief.sheta@mans.edu.eg),

Dr. Heba Mohamed Ahmed Abdou, Lecturer, Dept. of Architectural Engineering, Faculty of Engineering, Mansoura University (arch_heba84@mans.edu.eg) 
r. قضية المياه على مستوي العالم

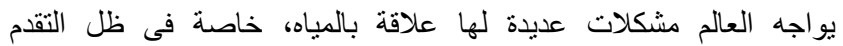

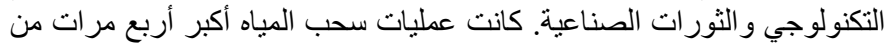

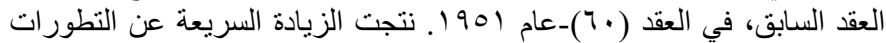

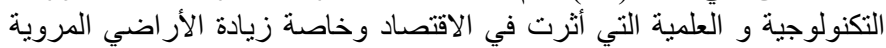

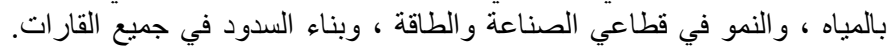

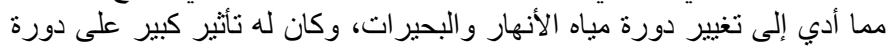

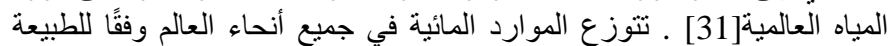

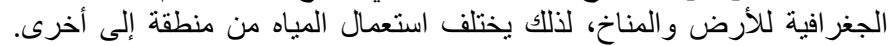

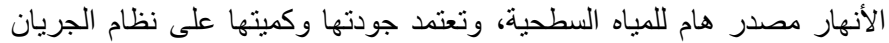

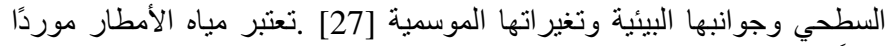

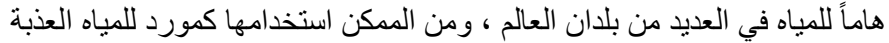

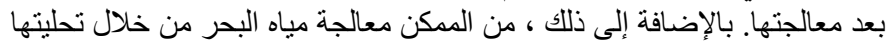

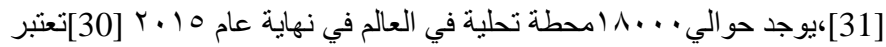

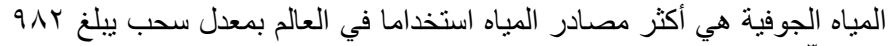

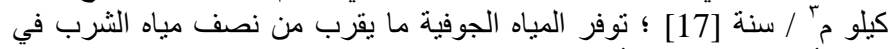

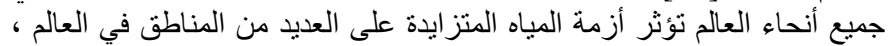

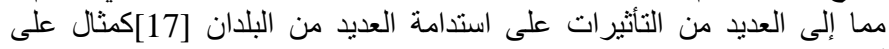

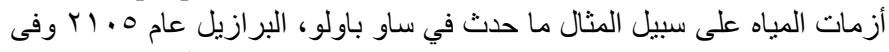

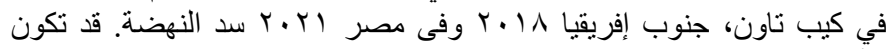

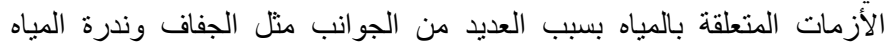

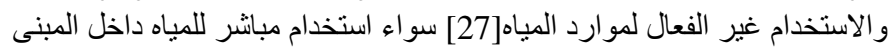

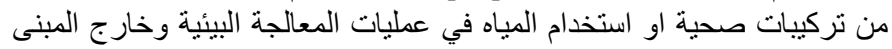

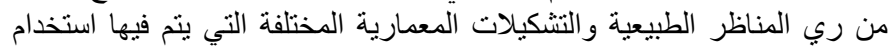

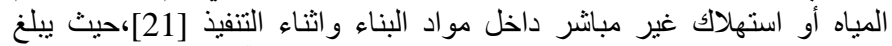

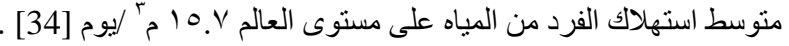

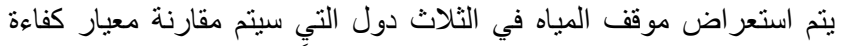

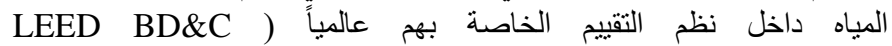

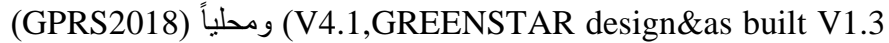
للتعرف على نثأة النظم من خلال قضية المياه بكل دولة من الدول المختار لها

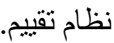

\section{r ـ ا موقف العياه بالولايات المتحدة الامريكية :}

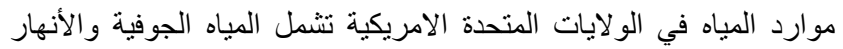

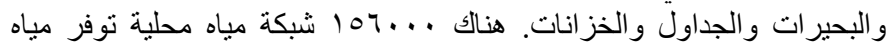

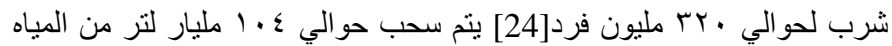

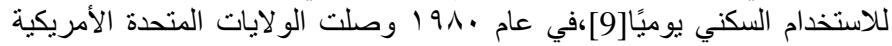

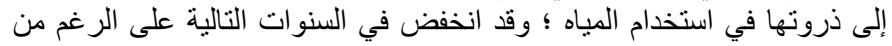

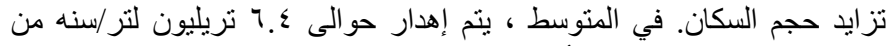

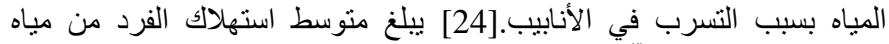

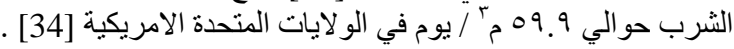

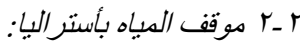

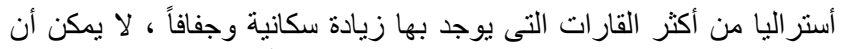

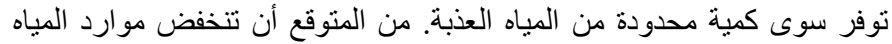

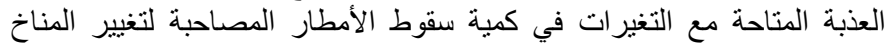

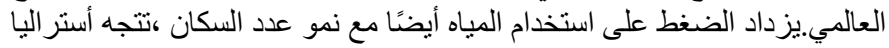

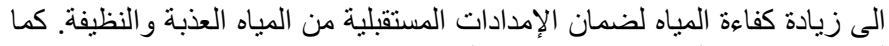

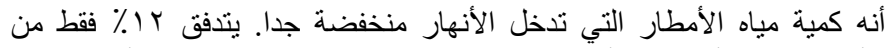

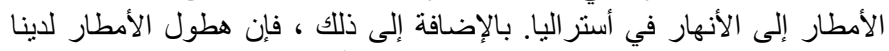

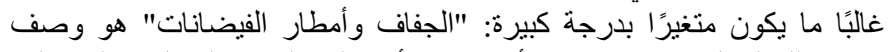

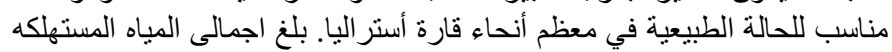

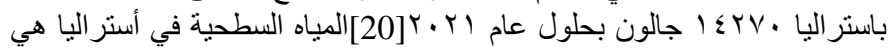

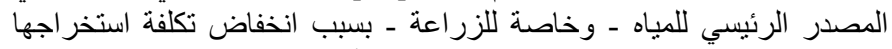

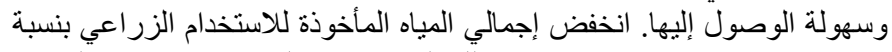

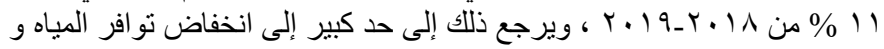

فهناك مجال لقياس استدامة المباني ومجال للتخطيط الحضري ومجال للتصميم

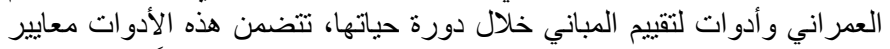

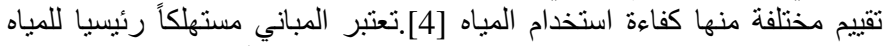

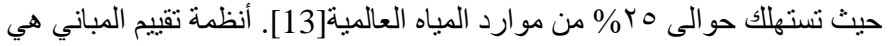

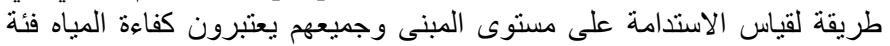
رئيسية ؛ يختلف وزن كفاءة المياه من نظام تصنيف إلى آلى آخر اعتمادًا على أهدافه والمتطلبات المحلية. تمثل فئة كفاءة المياه داخل نظام تقييم المباه

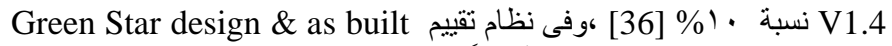

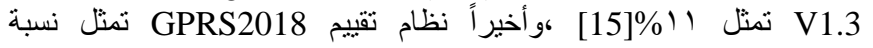

$[28] \%$ r.

\section{ا ـ ا أشكالية البحث:}

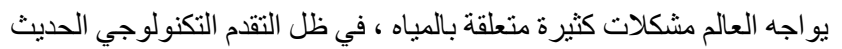

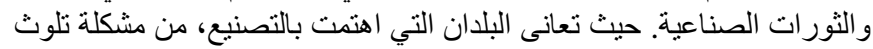

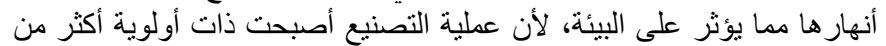

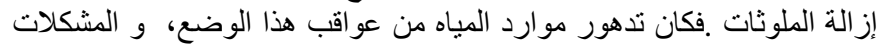
البيئية أصبحت أخطر المشكلات الثرات التي تواجه كثير من الأقاليم والبلاد،هو الثروة الثران

المائية العربية على رأسهم [3].

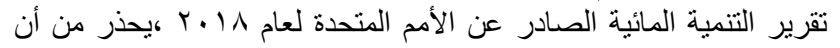

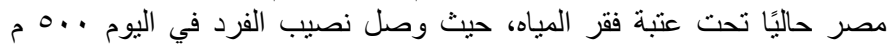

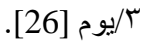
نستخلص من ذلك أنه حتى ولو لم يتأثر نصيب مصر من ماء النيل بإنشاء

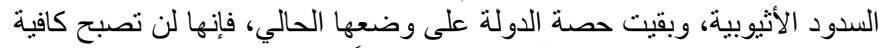

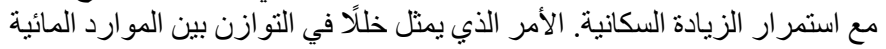

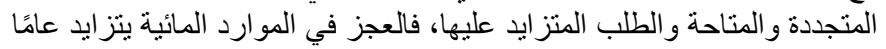

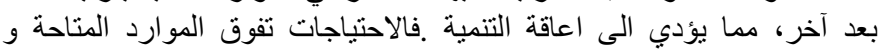

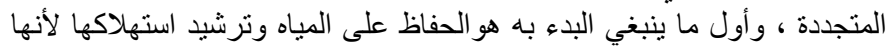

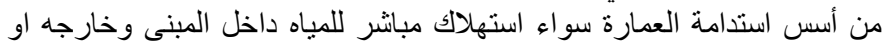
استهلاك غير مباشر للمياه داخل مو اد البناء.

r r o هدف البحث.

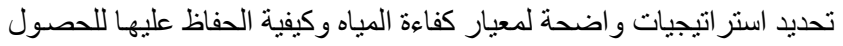

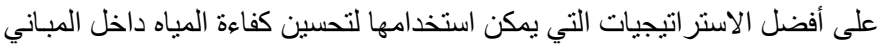

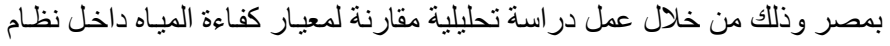

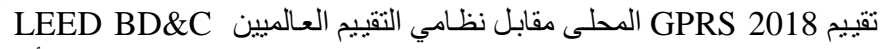

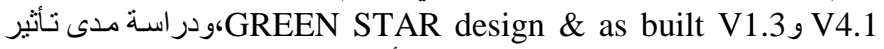
المياه على العمارة الخضر اء، وكيفية تحسين أدائها وكفاءتها.

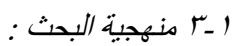

تنقسم منهجية البحث الى ثلاث اطار ات: اطار نظري و اطار تحليلي مقارن واطار تطبيقي

$$
\text { أولا: الدنهج النظري: النمي }
$$

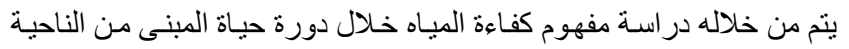

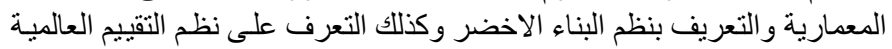
و المحلية وأسباب اختيار نلك النظم

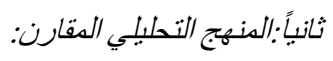

دراسة تحليلية مقارنة لمعيار كفاءة المياه داخل نظام تقييم G4. مقابل نظامي التقييم العالميين LEED BD\&C V4.1 و و GEEN STAR design \& as built V1.3

$$
\text { ثالثاً: المنهج التطبيقي: }
$$

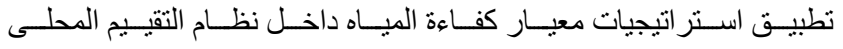
على مبنى شركة مياه الثرب و الصرف الصحي بالدقهلية 


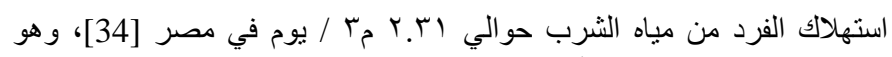

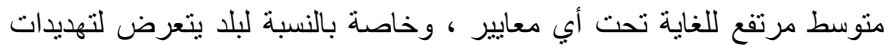

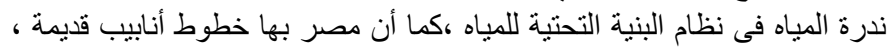

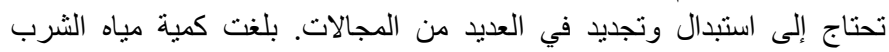

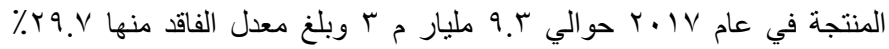

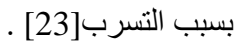

عند مقارنة نصيب الفرد من استهلاك المياه في اليوم للبلدان الثلاثة المختارة

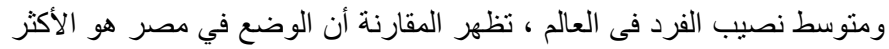

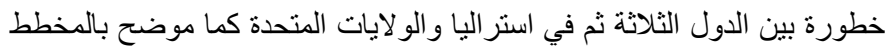

رقم) خطورة (ب)

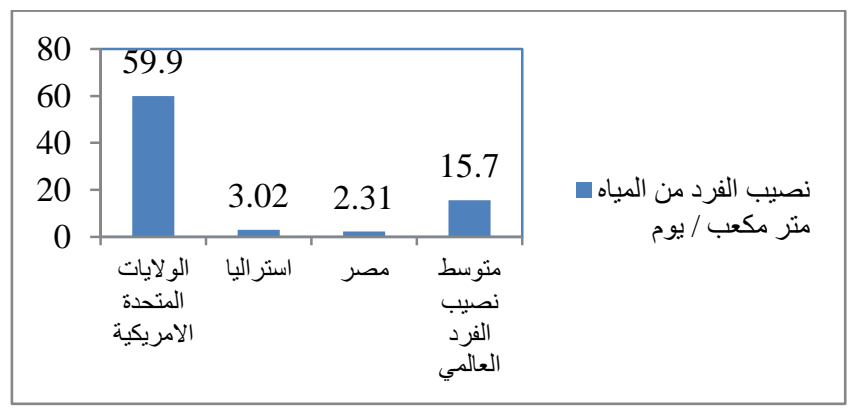

مخطط رقم (r ) :يوضح مقارنة متو سط نصيب الفرد بالدول المختارة مقارنة بمتوسط

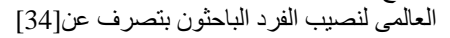

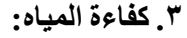

كفاءة استخدام المياه لها تعريفان رئيسيان: [32]

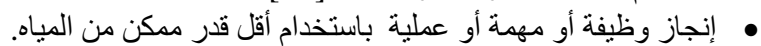

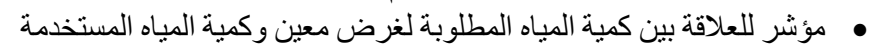

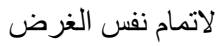

بـ ـ ا العلاقة بين كفاءة المياه والحفاظ عليها :

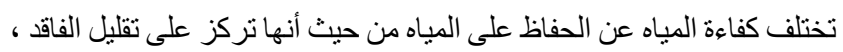

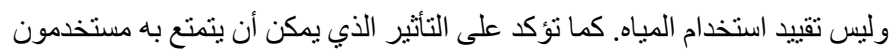

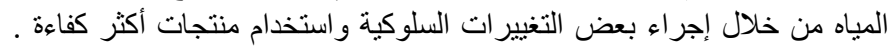

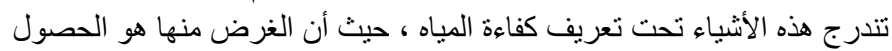

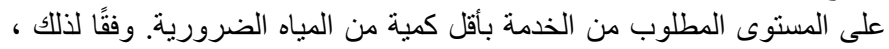

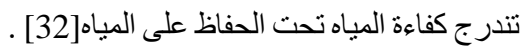

\section{؛ كفاءة استخدام المياه خلال دورة حياة المبني}

يؤدي تحسين كفاءة المياه في المباني إلى توفير الطاقة وتقليل تكاليف ميـاه

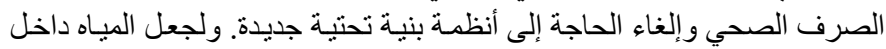

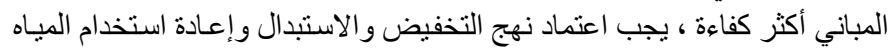

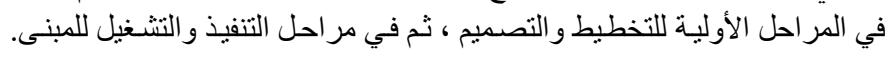

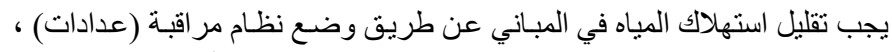

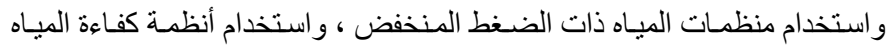

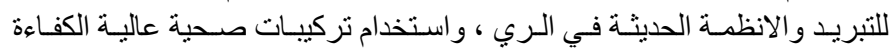

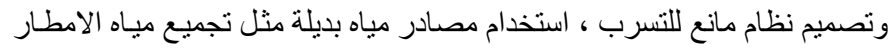

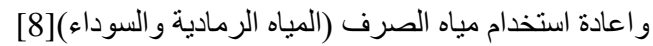

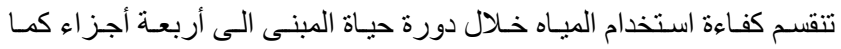

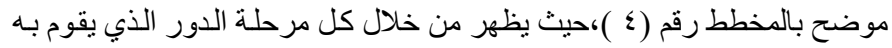
المعماري

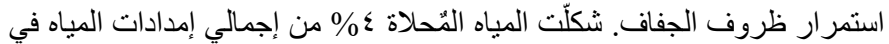

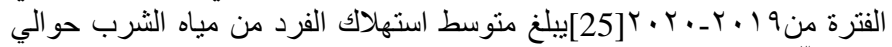

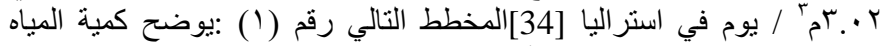

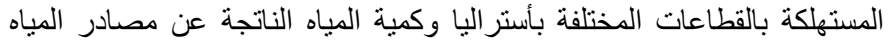

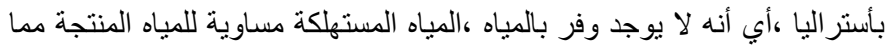
يؤثر على كفاءة المياه داخل المباني وبالتالي يؤثر على التى استدامة المباني الخضر الهاء.

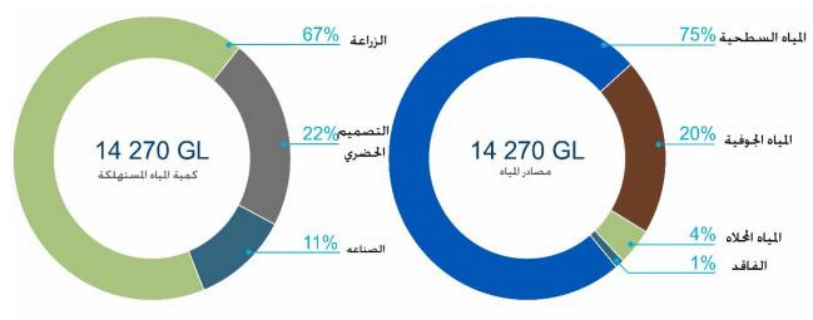

مخطط رقم ( ) : توزيع المياه بأستر اليال20]

r r r r r موقف المباه بمصر:

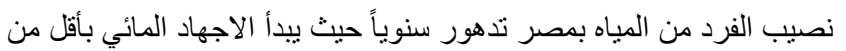

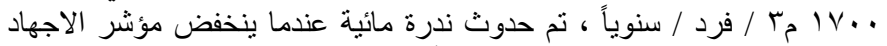

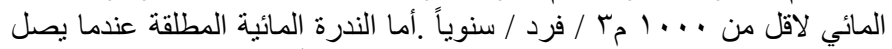

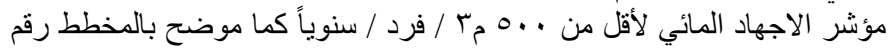

[5] (Y)

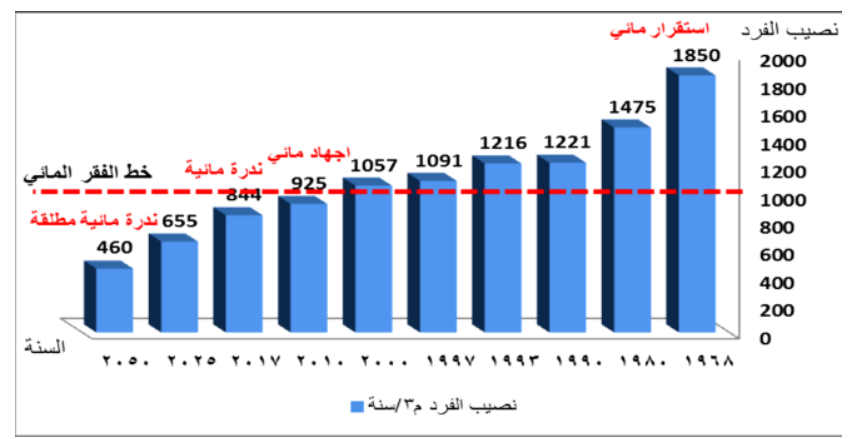

مخطط رقم (r) : تطور درجة الاجهاد المائي في مصر بالانحر اف عن خط الفقر المائي[5]

مصر تعتمد بنسبة 97\% على مياه نهر النيل ، حيث يتم توليدها من خارج

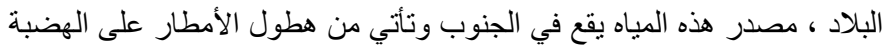

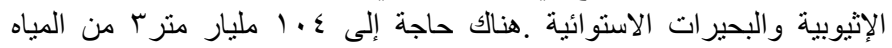

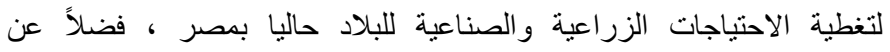

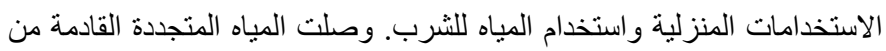

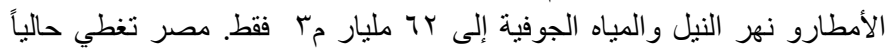

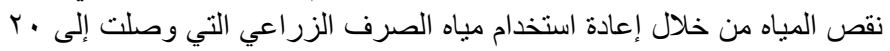

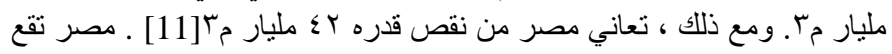

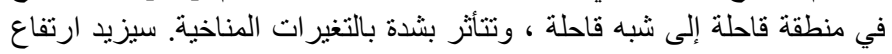

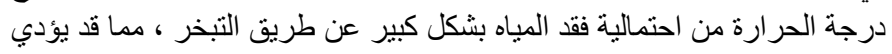

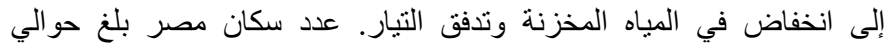

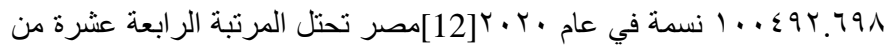

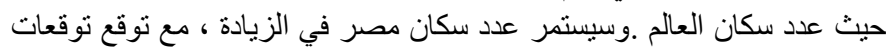

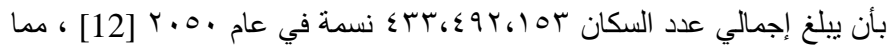

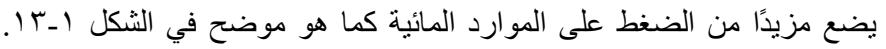
أصبحت مصر الآن تحت خط الفقر بمعدل ل . .

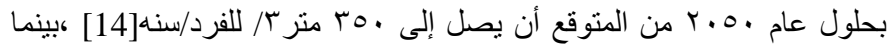

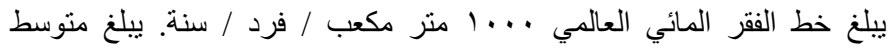




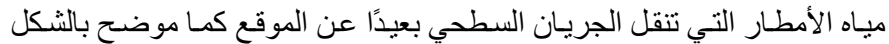

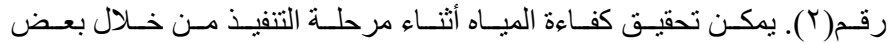

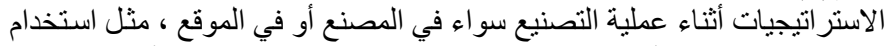

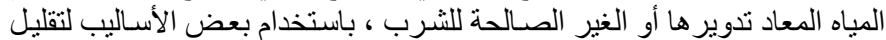

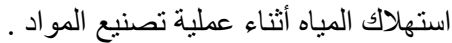
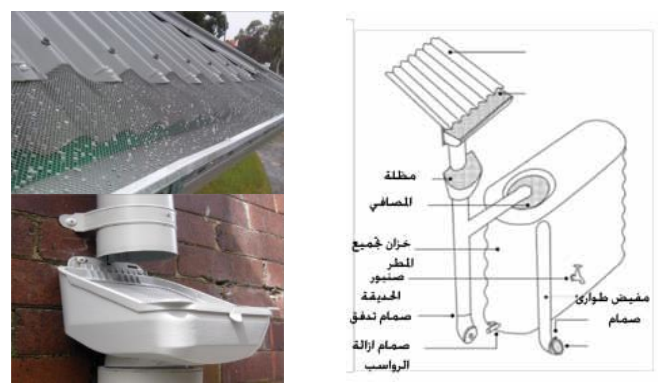

شكل رقم(ץ): نظام لتجميع مياه الأمطار بو اسطة المصمم المعماري[25]

ــ ـ مرحلة التشغيل والصبانة [7]:

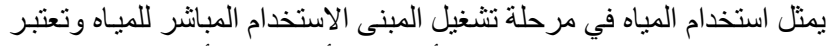

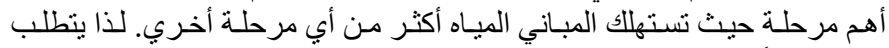

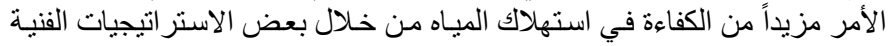

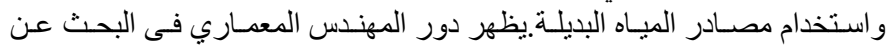

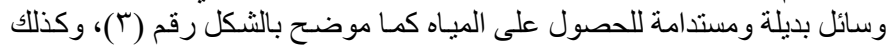

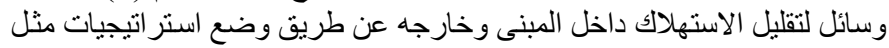

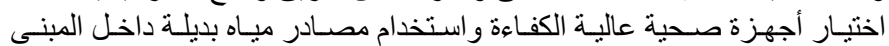

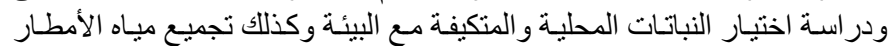

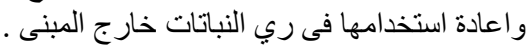

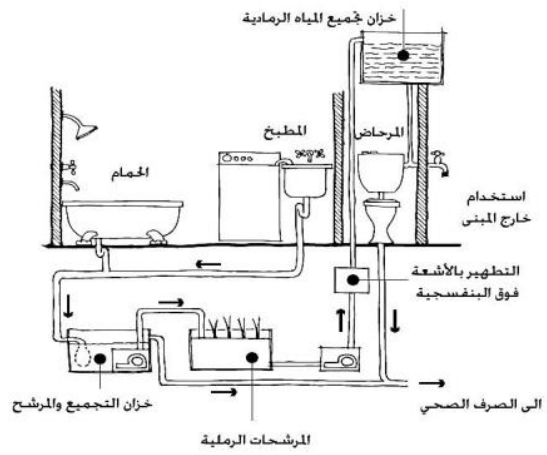

شكل رقم(؟) نظام لإعادة استخدام مياه الصرف بو اسطة المصمم المعماري[25]

\section{• مـ مفوم نظم التقييم البيئي :}

هي تحقيق اداة تقييمية للمباني من خلال وضع موم معايير و و منهجية

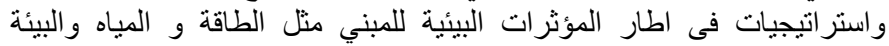

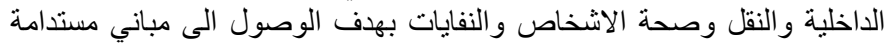

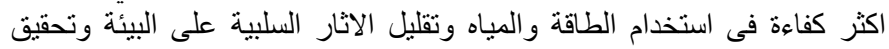

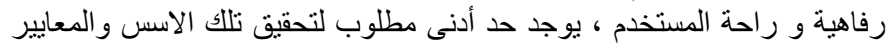

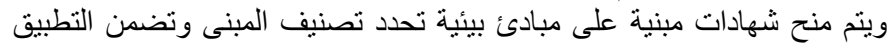

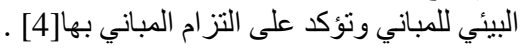

[4]: الكدف من نظم التقبيم البيئية • وضع معايير واستر اتيجيات لعلاقة المبني بالبيئة

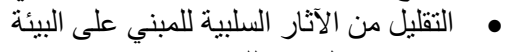

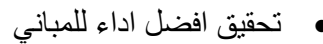
دعم الاستثمار للمباني فى سوق العمل

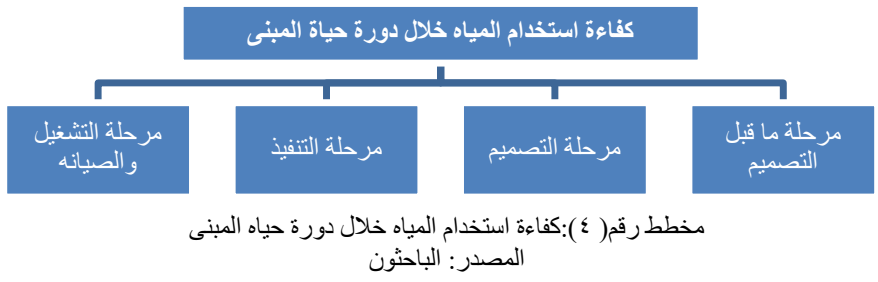

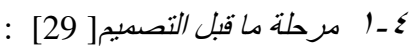

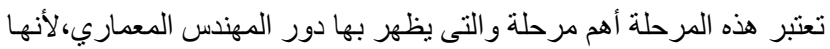

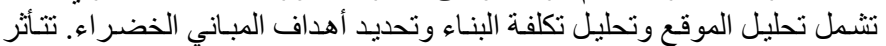

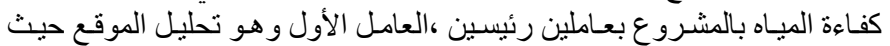

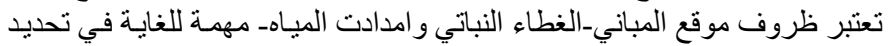

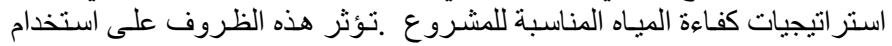

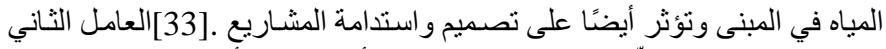

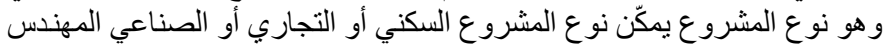

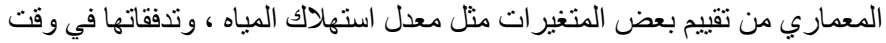

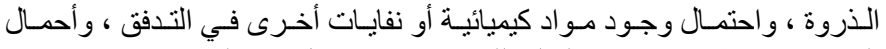

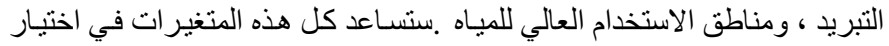

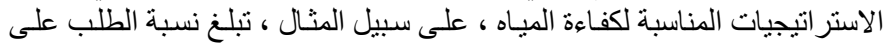

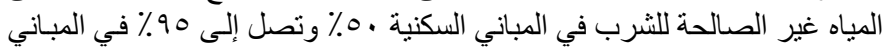

[33] التجارية

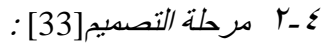

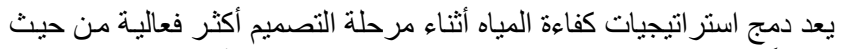

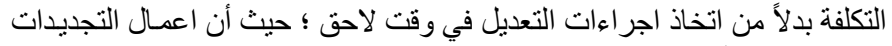

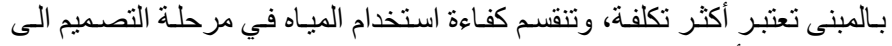

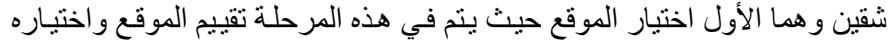

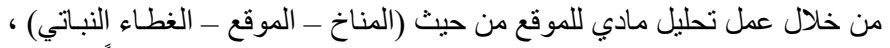

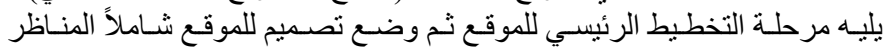

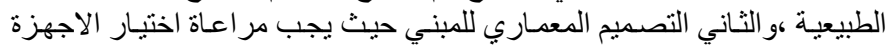

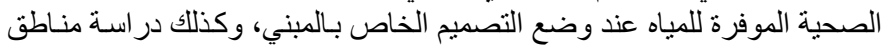

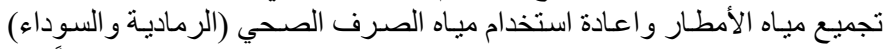

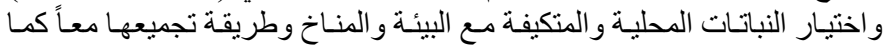

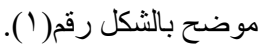

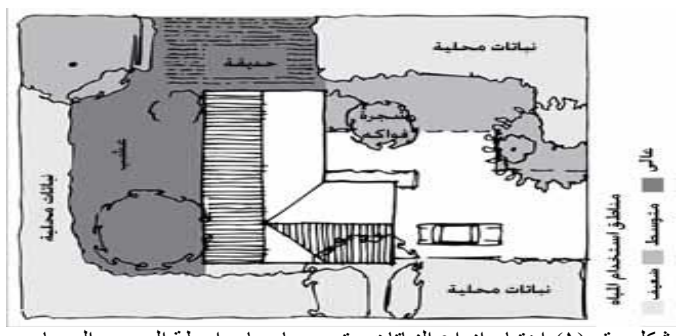

شكل رقم (1):اختيار انو اع النباتات وتجميعها معا بواسطة المصمم المعماري

أو مهنس تنسيق الموقع[25]

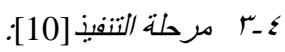

تعتبر صناعة البناء هي أكبر مستهلك للمواد الخـام في العالم اليوم بعد إنتاج

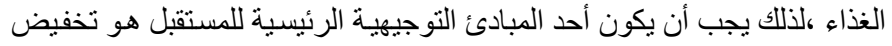

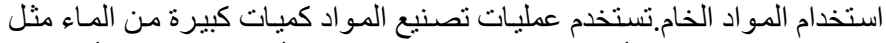

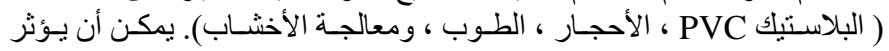

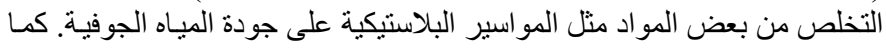

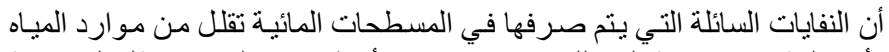

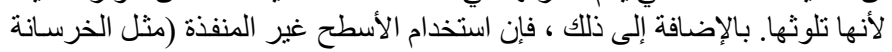

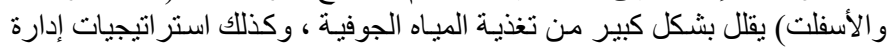




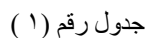

مكونات نظام LEED BD\&C V4.1 المصدر:الباحثون بتصرف عن[36]

\begin{tabular}{|c|c|}
\hline النقاط - اط & المعيار \\
\hline 1 & العملية التكاملية \\
\hline 17 & الموقع والنقل \\
\hline 1. & المواقع المستد/مة \\
\hline 11 & كفاءة المباه \\
\hline Tr & الطاقة والغلاف الجوي \\
\hline$\pi$ & المواد والدوارد \\
\hline 17 & جودة البيئة الداخلبة \\
\hline 7 & الابداع \\
\hline$\varepsilon$ & الاولوية الاقلبمية \\
\hline 11. & الاجمالى \\
\hline
\end{tabular}

من خلال الجدول السابث رقم ( ) ( ) ومن خلال المخطط التالي رقم (T) يتضح

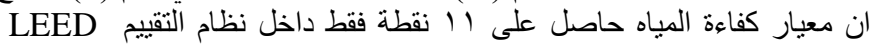

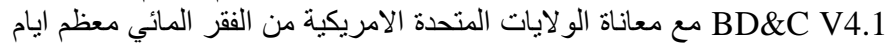

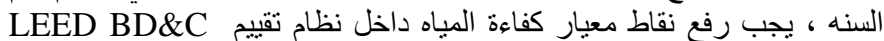

V4.1

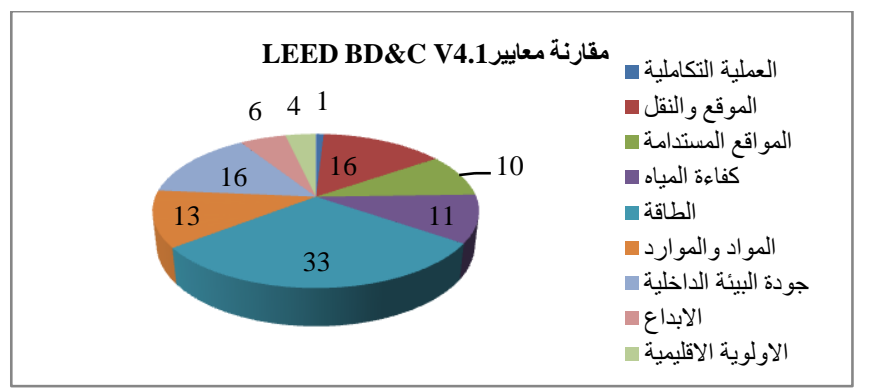

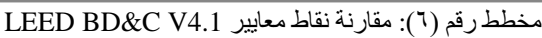

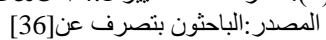

$$
\text { وناصر الزمامية : عناصر محدات التقييم الى قسمين : }
$$

يجب ان يستوفى المشروع جميع العناصر الالز امية والفشل في تحقيقها يحرم

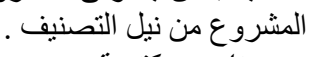

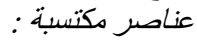

لا يفترض بالمشروع أنه يجب ان تتحقق نقاط الاعتماد لهذه العناصر ، ولكن الأن

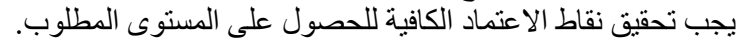
وفيما يلي شر ح تفصيلي لمحدد كفاءة المياه بالنظام :

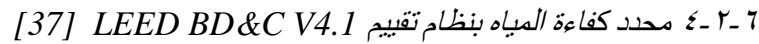

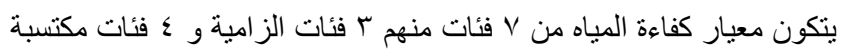

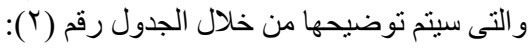

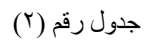

\begin{tabular}{|c|c|}
\hline النقاط & الفئذة \\
\hline & فئات الزامية \\
\hline الزامي & 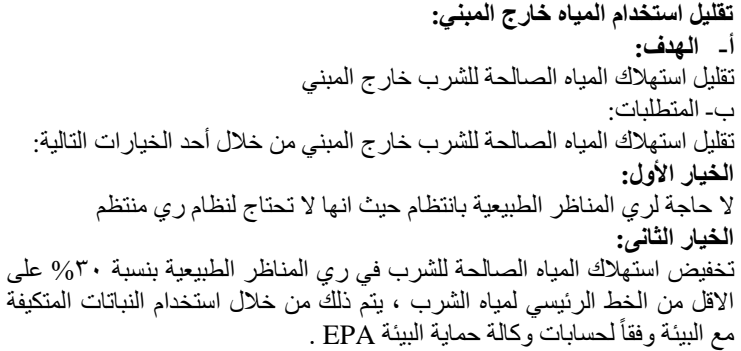 \\
\hline
\end{tabular}

فئات معيار كفاءة المياه بنظام تقييم الريادة فى الطاقة و التصميم البيئي

المصدر :الباحثون بتصرف عن [37]
• • انشاء المباني المستدامة بكثرة

• • يادة الاثر البيئي للمباني في مرحلة التشغيل و الصيانة

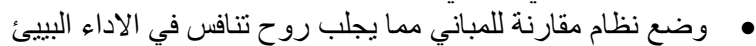

\section{T. بظام تقييم الريادة فى الطاقة و التصميم البيئي) ENERGY AND ENVIRONMENTAL DESIGN}

$$
7 \text { ـ } 1 \text { سبب /ختبار نظام LEED }
$$

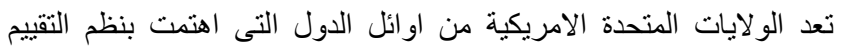

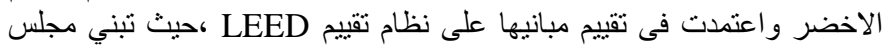

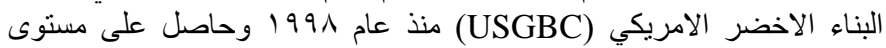
عضوية Established من World GBC ، كما أن الو لايات المتحدة الامريكية

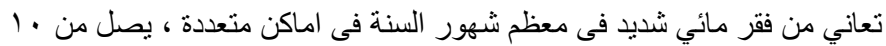

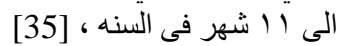

7 ـ التعريف بنظام تقبيم الريادة فى الطاقة و التصميم البيئي:(19) [19ED)

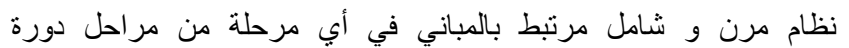

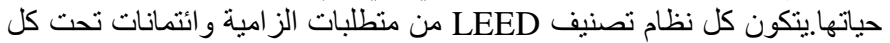

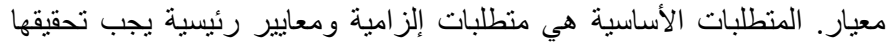

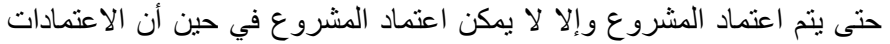

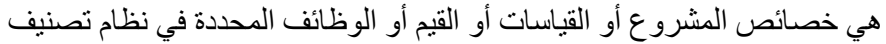
LEED

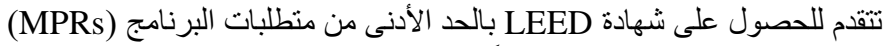

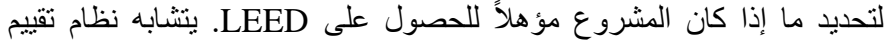
LEED و نظام تقييم GPRS بنسبة كبيرة جدا على الرغم من وجود التح اختلافات مكانية بين البلدين.

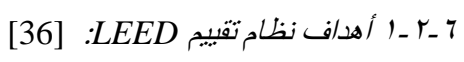
• • • • • • • •

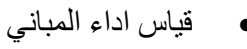

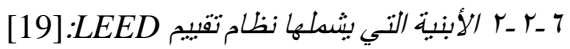

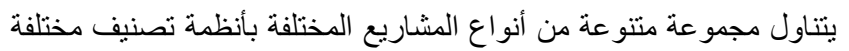

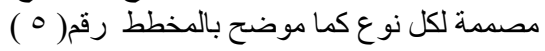

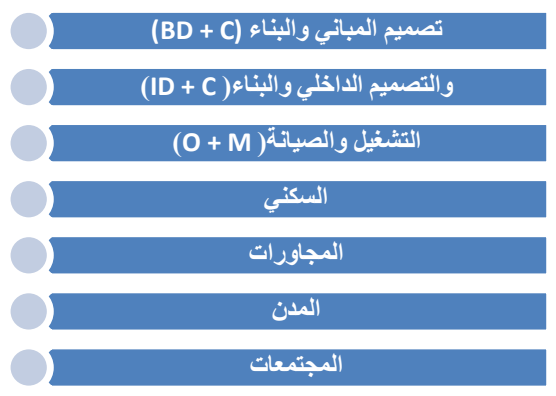

مخططر رم (o ) : المشاريع المرتبطة بنظام LEED المصدر :الباحثون بترف عن[19]

تم اختيار نظام LEED BD\&C V4.1 حيث انه موجه للمباني في مرحلة التصميمات والمباني الجديدة والتجديدات مثل نظام تقييم GPRS2018 وسيتم التعرف عليه كالآتي: - التياني

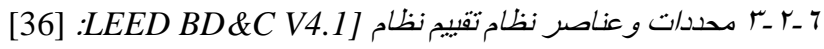
يحتوى نظام تقييم LEED BD\&C V4.1 على مجمو عة من المحددات

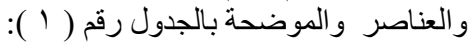




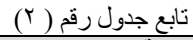

\begin{tabular}{|c|c|}
\hline النقاط & الفئة \\
\hline \multicolumn{2}{|r|}{ فئات مكتسبة } \\
\hline 1 & 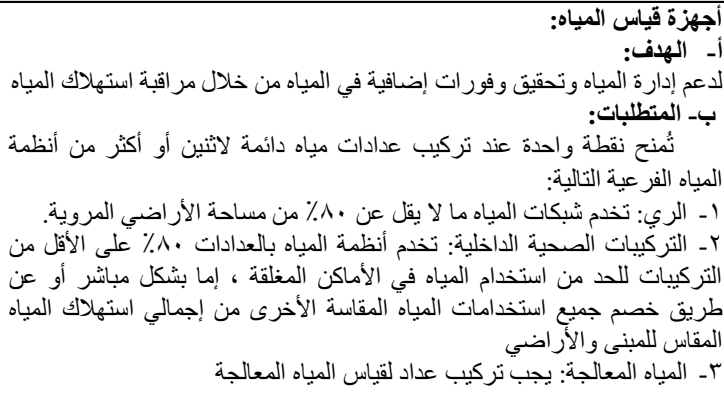 \\
\hline 11 & \\
\hline
\end{tabular}

\section{V. نظام تقييم النجم الأخضر بأستراليا GREEN STAR:}

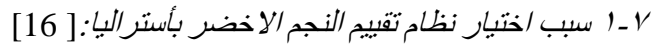

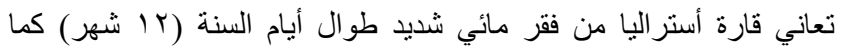

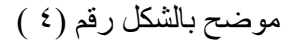

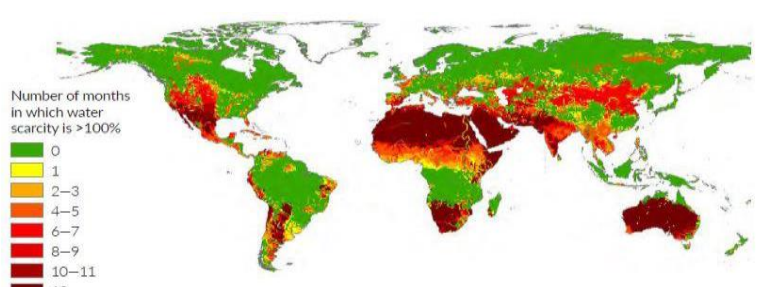

شكل رقم ( §) : عدد الاشهر التى تعانى منها البلاد من ندرة المياه[22]

r r التعريف بنظام تقبيم النجم الأخضر بأستراليا GREEN STAR:

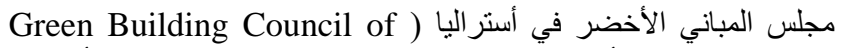
Australia (GBCA green star

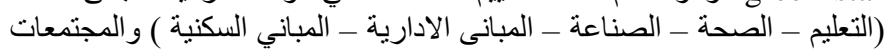

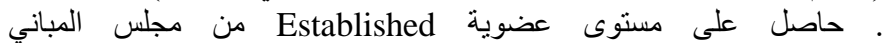
الأخضر ييتخدم هذا النظام عملية تقيم قوية وشفافة ومستقلة

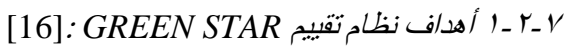

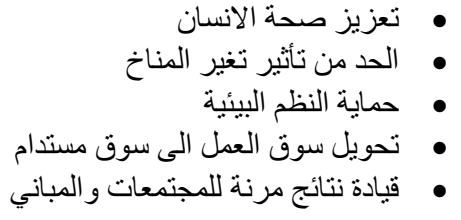

[16] GREEN STAR الأبنية التي يشملها نظام تقبيم r-V يتناول مجمو عة متنو عة من أنواع المشاريع المختلفة بأنظمة تصنيف مختلفئة

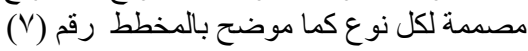

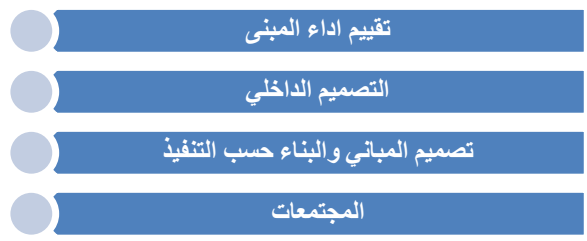

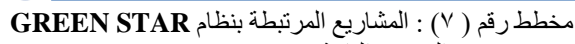

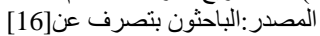

\begin{tabular}{|c|c|}
\hline النقاط & الفئة \\
\hline الز امي & 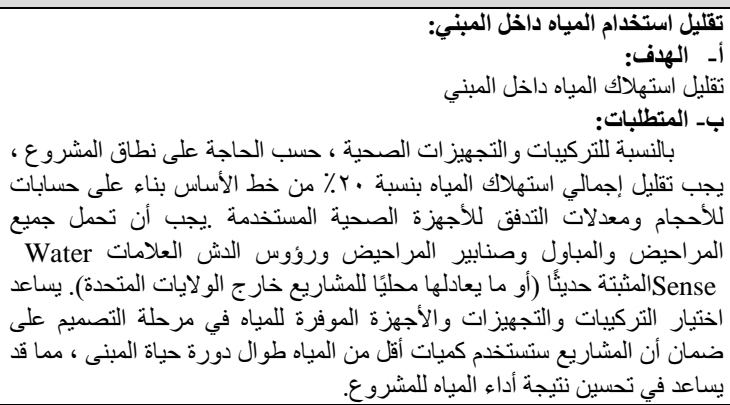 \\
\hline 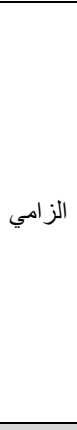 & 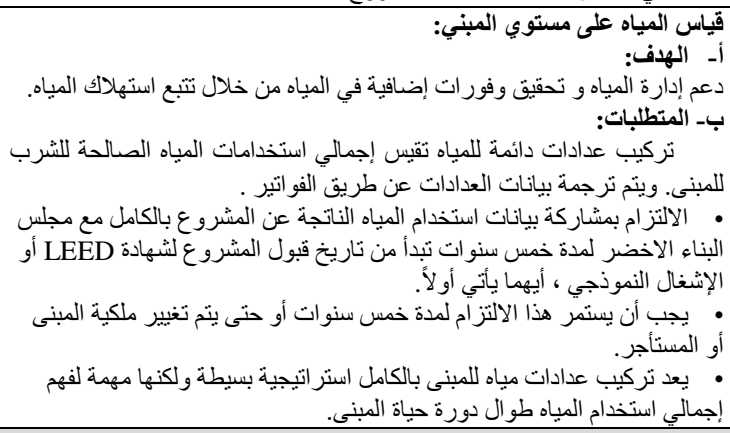 \\
\hline \multicolumn{2}{|r|}{ فئات مكتسبة } \\
\hline r & 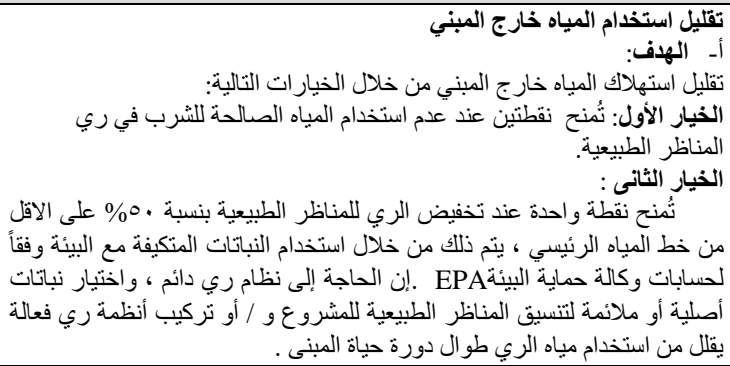 \\
\hline 7 & 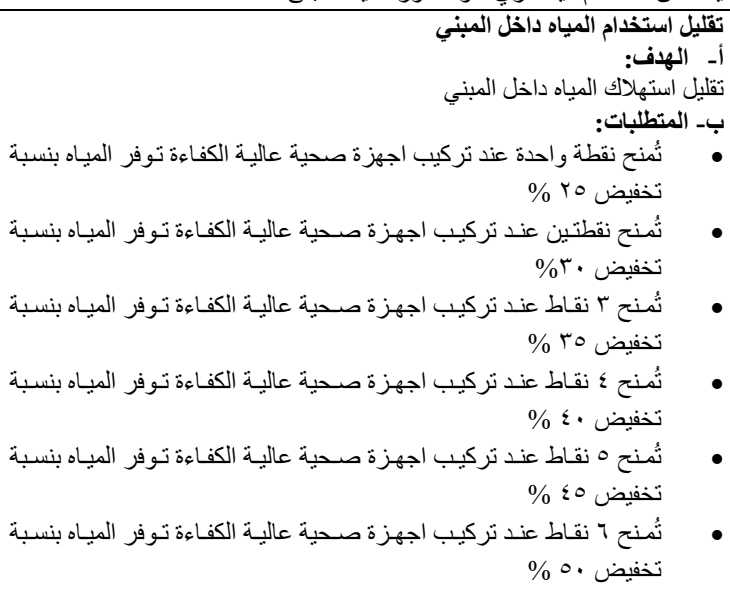 \\
\hline r & 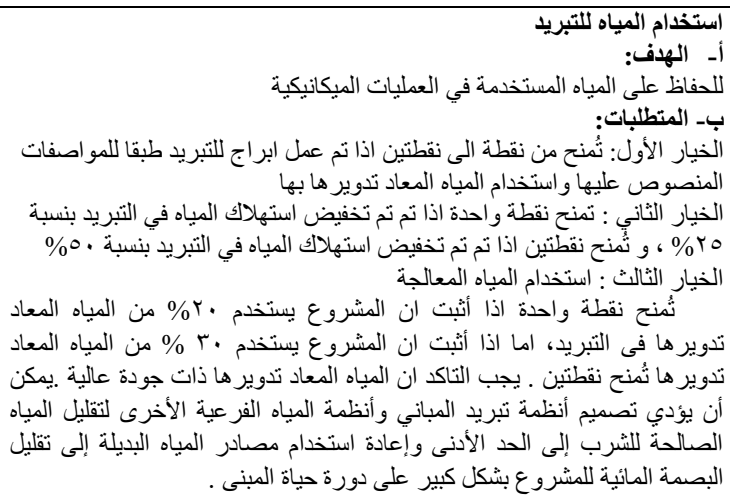 \\
\hline
\end{tabular}




\begin{tabular}{|c|c|}
\hline & 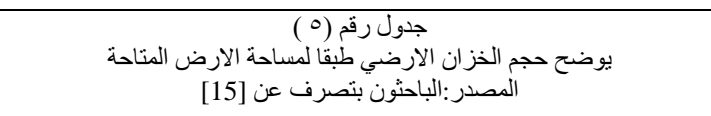 \\
\hline & 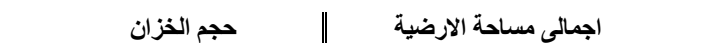 \\
\hline & ro.. \\
\hline & $0 \ldots$ \\
\hline & $1 \ldots$ \\
\hline & $r \ldots$ \\
\hline r & 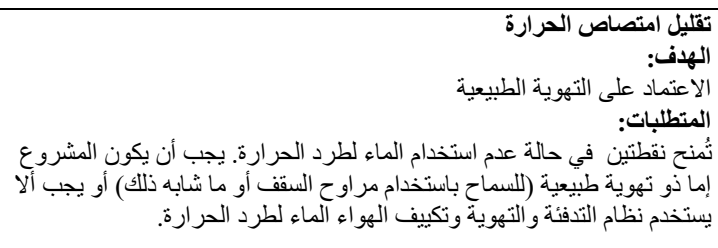 \\
\hline 1 & 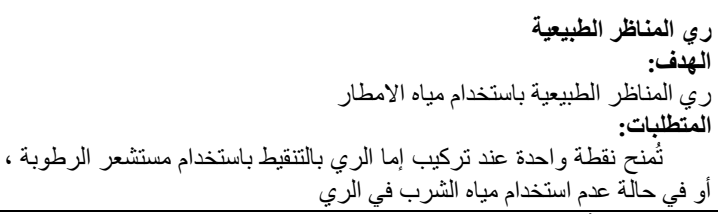 \\
\hline 1 & 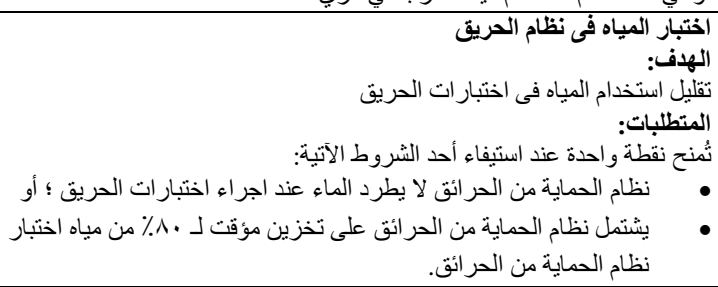 \\
\hline 7 & اجمالى نقاط فئات معيار كفاءة المياه \\
\hline
\end{tabular}

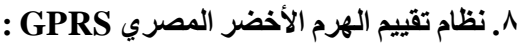

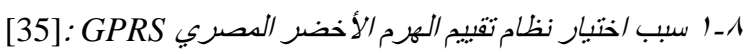

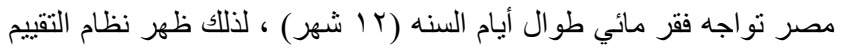

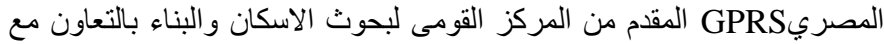

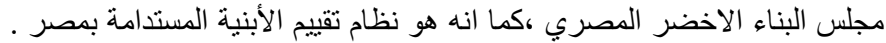

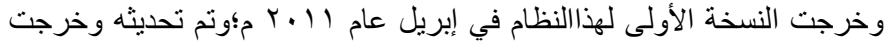

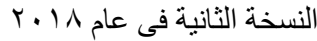

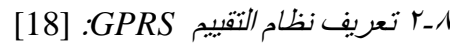

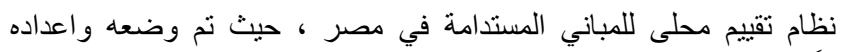

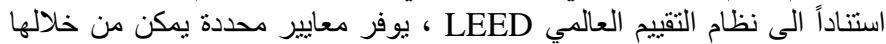

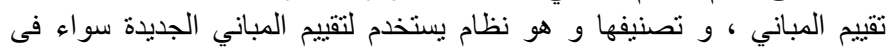

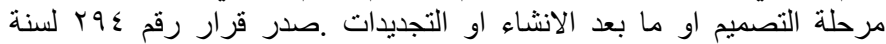

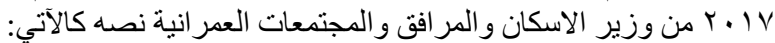

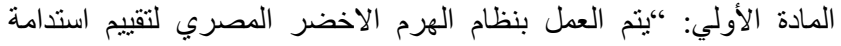

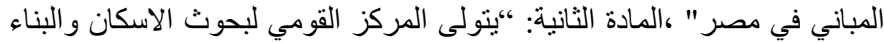

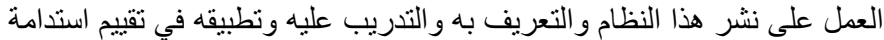

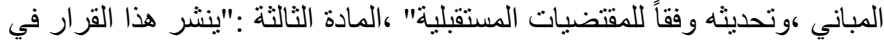

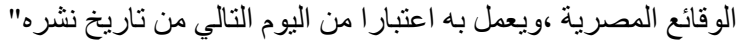

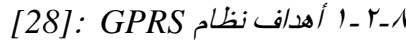

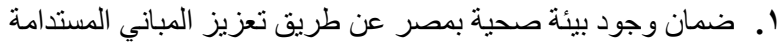

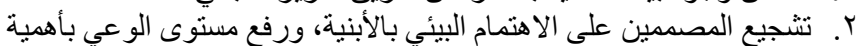
الأبنية المستدامة.

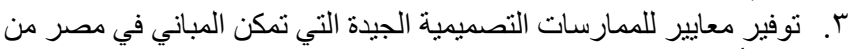

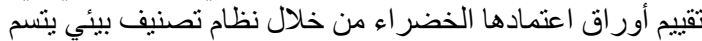
بالمصداقية و التحدي و الثفافية الثنافية ع. تحفيز الوعي والطلب على المباني الخضر اء المستدامة
تم اختيار نظام Green Star Design \& As Built V1.3 حيث انه موجه للمباني فى مرحلة التصميمات و المباني الجديدة و التجديدات مثل نظام تقييم GPRS2018 وسيتم التعرف عليه كالآتي:

Green Star Design \& As Built محددات وعناصر نظام تقبيم r r. r.V [15]:V1.3

يحنوى نظام تقييم Green Star Design \& As Built V1.3 مجمو عة من المحددات و العناصر و والموضحه بالجدول رقم (r):

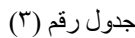

Dرجات معايير الاعتماد بنظام :لدمام

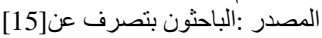

\begin{tabular}{|c|c|}
\hline النقاط & 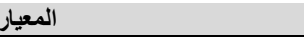 \\
\hline $1 \varepsilon$ & الادارة \\
\hline IV & جودة البيئة الداخلية \\
\hline rr & الطاقة \\
\hline 1. & النقل والمواصلات \\
\hline ir & المباه \\
\hline $1 \leq$ & المواد والخامات \\
\hline 7 & /ستعمالات الاراضىى وعلم البيئة \\
\hline 0 & الانبعاثات \\
\hline 1. & الابداع ال الاع \\
\hline 11. & \\
\hline
\end{tabular}

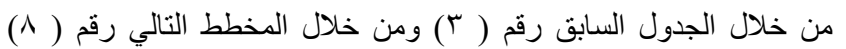

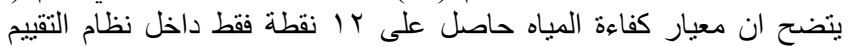
Green Star Design \& As Built V1.3 المائي طوال ايام السنه ، يجب رفع نقاط معيار كفاءة المياه داخل نظام تقييم Green Star Design \& As Built V1.3

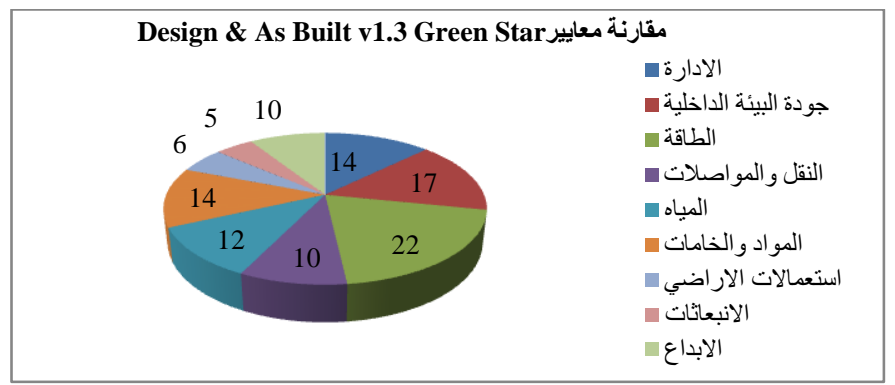

Green Star Design \& As Built V1.3 مخطط رقم ( ^) : مقارنة نقاط معايير نظام البطام المصدر:الباحثون

Green Design \& As Built V1.3 كحد كفاءة المياه بنظام تقبيم : T-V : [15] Star يتكون معيار كفاءة المياه من V فئات منهم ب فئات الزامية و ع فئات مكتسبة

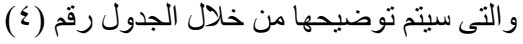

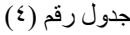

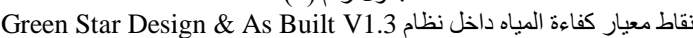
المصدر:الباحثون بتصرف عن[15]

\begin{tabular}{|c|c|}
\hline النقاط & الفئة \\
\hline 1 & 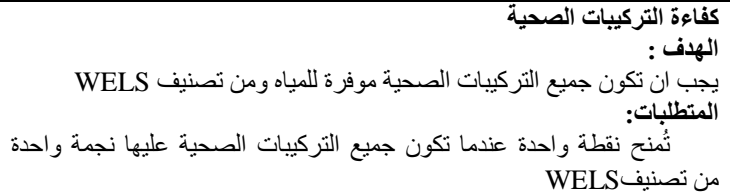 \\
\hline 1 & 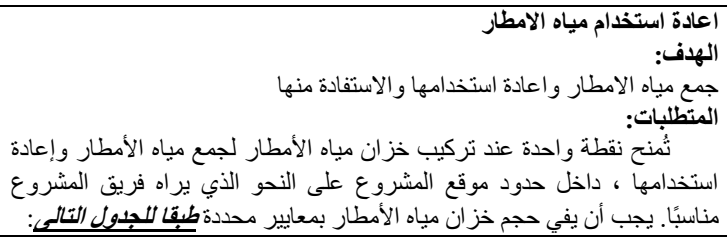 \\
\hline
\end{tabular}




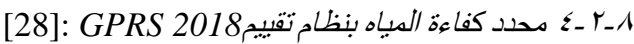

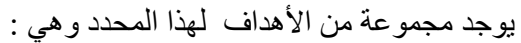

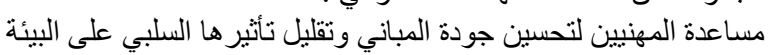
تطوير وتطبيق استر اتيجية متكاملة للمبياه

تقليل الطلب على كمية المياه الداخلية و الخارجية.

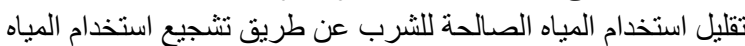

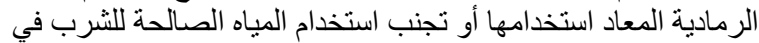

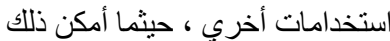
تحقيق كفاءة المياه بالمناظر الطبيعية ألمنية

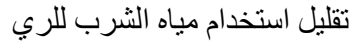

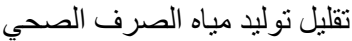

ويوضح الجدول رقم (V)عناصر ونقاط هذا المحدد

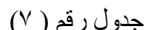

يوضح نقاط الاتثمان ودرجاتها في معيار كفاءة المياه داخل نظام

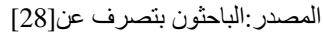

\begin{tabular}{|c|c|}
\hline النقاط & الفئة \\
\hline \multirow[t]{2}{*}{ r. } & 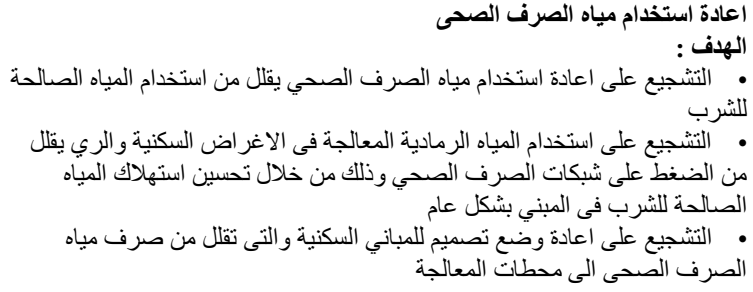 \\
\hline & 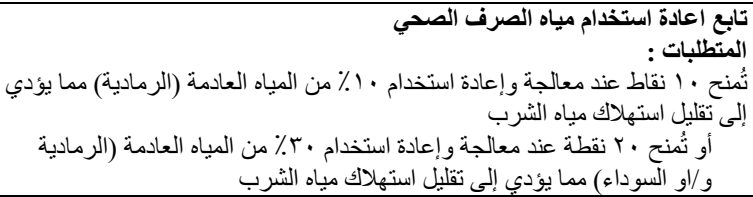 \\
\hline 1. & 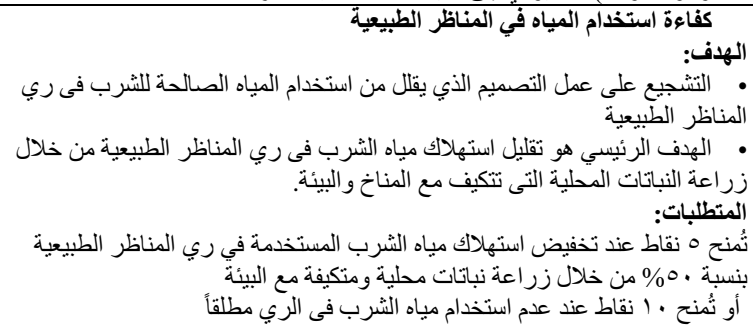 \\
\hline$r$ & 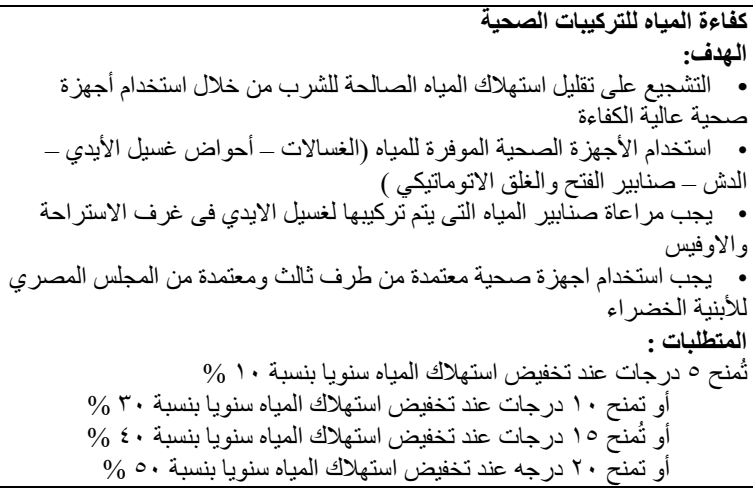 \\
\hline 1. & 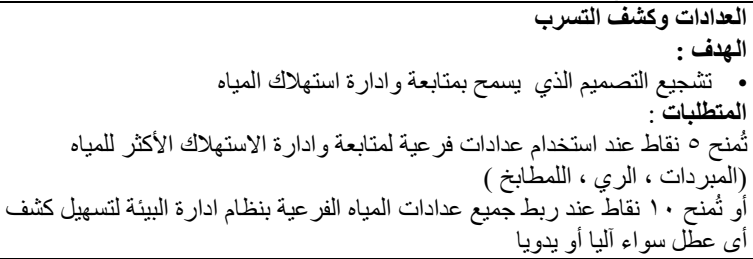 \\
\hline 7. & \\
\hline
\end{tabular}

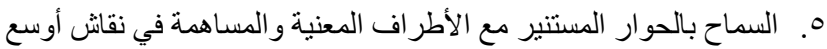

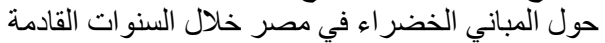

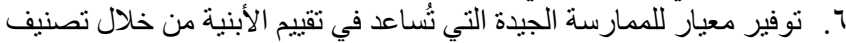

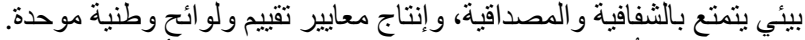

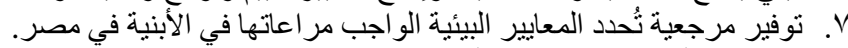

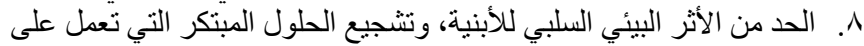
تقليله. 9. السماح بحو ار مستنبر مع كل الأطر اف المعنية، و المساهمة في تطوير

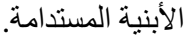

• 1 استغلال الموارد الطبيعية بما يضمن الحفاظ على المخزون الاستر اتيجي و هوية البيئة المصرية.

[6]: GPRS الأبنية التي يشملها نظام تقبيم r- r-1

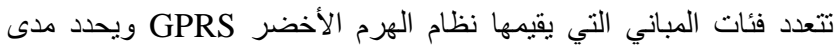

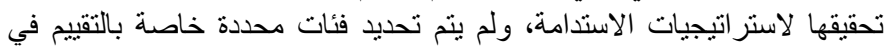

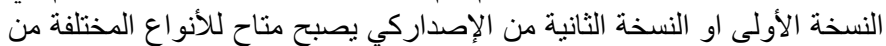

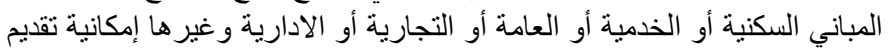

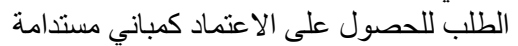

[28]: GPRS 2018 r- T_A

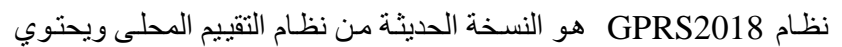

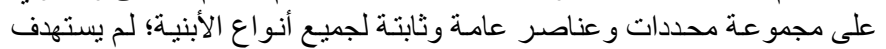

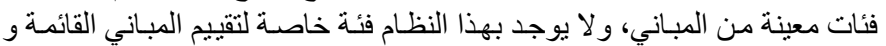

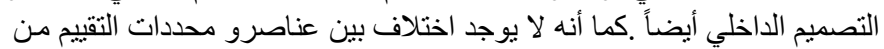

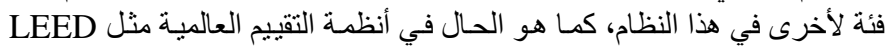
ان GREEN STAR design \& as built V1.3 BD\&C V4.1

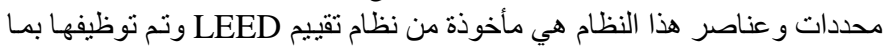
يتناسب مع المباني في مصر ، ويوضح الجدول رقم ( ؟) محددات هذا النظام :

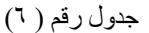

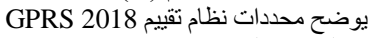

المصدر:الباحثون بتصرف عن [28]

\begin{tabular}{|c|c|}
\hline النقاط & المعايير \\
\hline «. & المو اقع المستدامة ، امكانية الوصول ، علم البيئة \\
\hline 07 & كفاءة استخدام الطاقة \\
\hline 7. & كفاءة استخدام المياه \\
\hline$r \varepsilon$ & المو اد و الموارد \\
\hline$r \varepsilon$ & جودة البيئة الداخلية \\
\hline 17 & الادارة \\
\hline 1. & الابتكار و القيمة المضافة \\
\hline rr. & الاجمالى \\
\hline
\end{tabular}

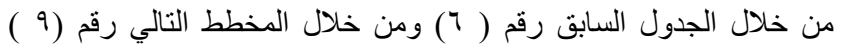

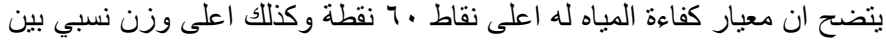

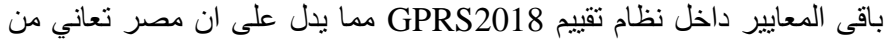
مشكلة فى موارد المياه وبالتالي يجب الإهل التقييم المحلى مكلى التى

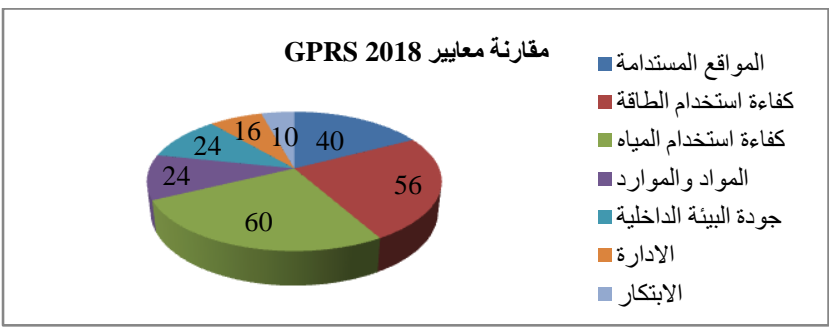

مخطط رقم (9 ): مقارنة معايير GPRS 2018 المصدر:الباحثون 


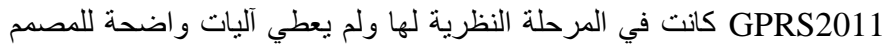
المعماري يستطيع منها تقييم المبنى وتحقيق متطلبات توفير المياه ، ولكن ولنئ النسخة

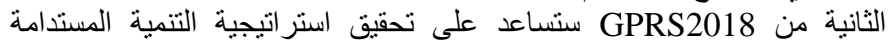

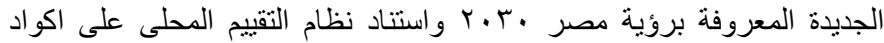

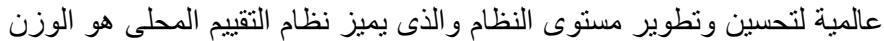

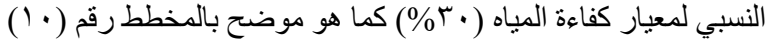

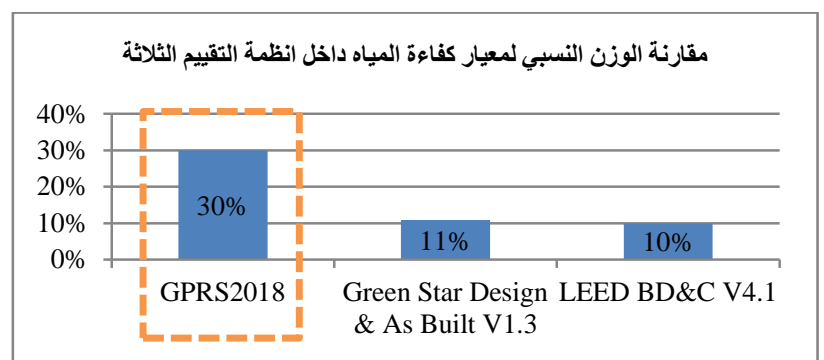

مخطط رقم ( • () :يوضح الوزن النسبي لمعيار كفاءة المياه داخل انظمة التقييم الثلاثة

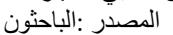

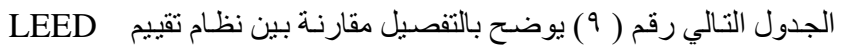
Green Star Design \& As Built V1.3 ونظام تقييم BD\&C V4.1 وكذلك نظام التقيم المحلى و

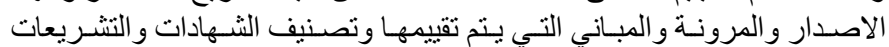

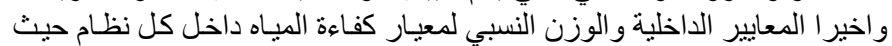

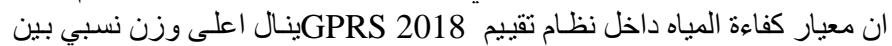

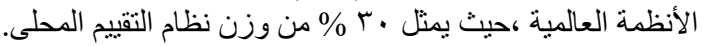

\section{9. مقارنة استر اتيجيات معيار كفاءة المياه داخل نظم التقييم المختارة}

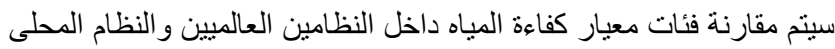

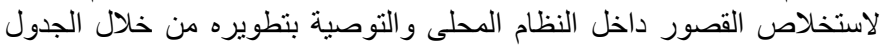

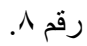

\begin{tabular}{|c|c|c|c|}
\hline \multirow[b]{2}{*}{$\begin{array}{l}\text { GPRS } \\
2018\end{array}$} & \multicolumn{3}{|c|}{ جدول رقم(^):مقارنة بين استر اتيجيات نظم التقييم الثلاثة } \\
\hline & $\begin{array}{c}\text { Green Star } \\
\text { Design \& As } \\
\text { Built V1.3 }\end{array}$ & $\begin{array}{c}\text { LEED } \\
\text { BD\&C } \\
\text { V4.1 }\end{array}$ & 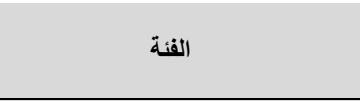 \\
\hline 1 & $\times$ & 1 & اعادة /ستخد/م مياه الصرف الصدي \\
\hline 1 & 1 & 1 & كفاءة /ستخدام المباه في المناظر الطبيعية \\
\hline 1 & 1 & 1 & كفاءة المباه للتركبيات الَصحبة \\
\hline 1 & $x$ & 1 & العدادات وكثف التنسرب \\
\hline 1 & 1 & 1 & قبياس المباه على مستوي المبني \\
\hline 1 & 1 & 1 & تقلبل استخد/م المباه خارج المبني \\
\hline 1 & 1 & 1 & تقليل استخد/م المباه داخل المبنبي \\
\hline$x$ & I & 1 & استخد/م المباه للتبريد \\
\hline$x$ & 1 & $x$ & اعادة استخد/م مباه الامطار \\
\hline$x$ & 1 & 1 & تقلبل امتصاص الحرارة \\
\hline$x$ & 1 & $x$ & اختبار المباه في نظام الحريق \\
\hline 1 & I & 1 & ري المناظر الطبيعية \\
\hline
\end{tabular}

يتضح من الجدول رقم (^) أن نظام تقييم LEED BD\&C V4.1 و ع نظام

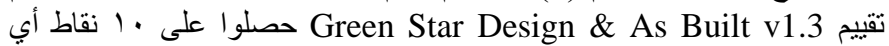
انهما من أكثر الانظمة اهتماما باستر اتيجيات معيار كفاءة المياه ، كمان ان نظام

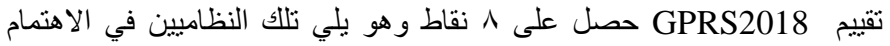

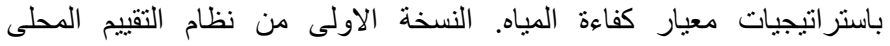

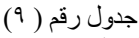

مقارنة بين نظم التقييم المختارة المصدر : الباحثُون بتصرف عن عن الدليل الارشادي لنظم الثقييم المختارة المصدر: الباحثون

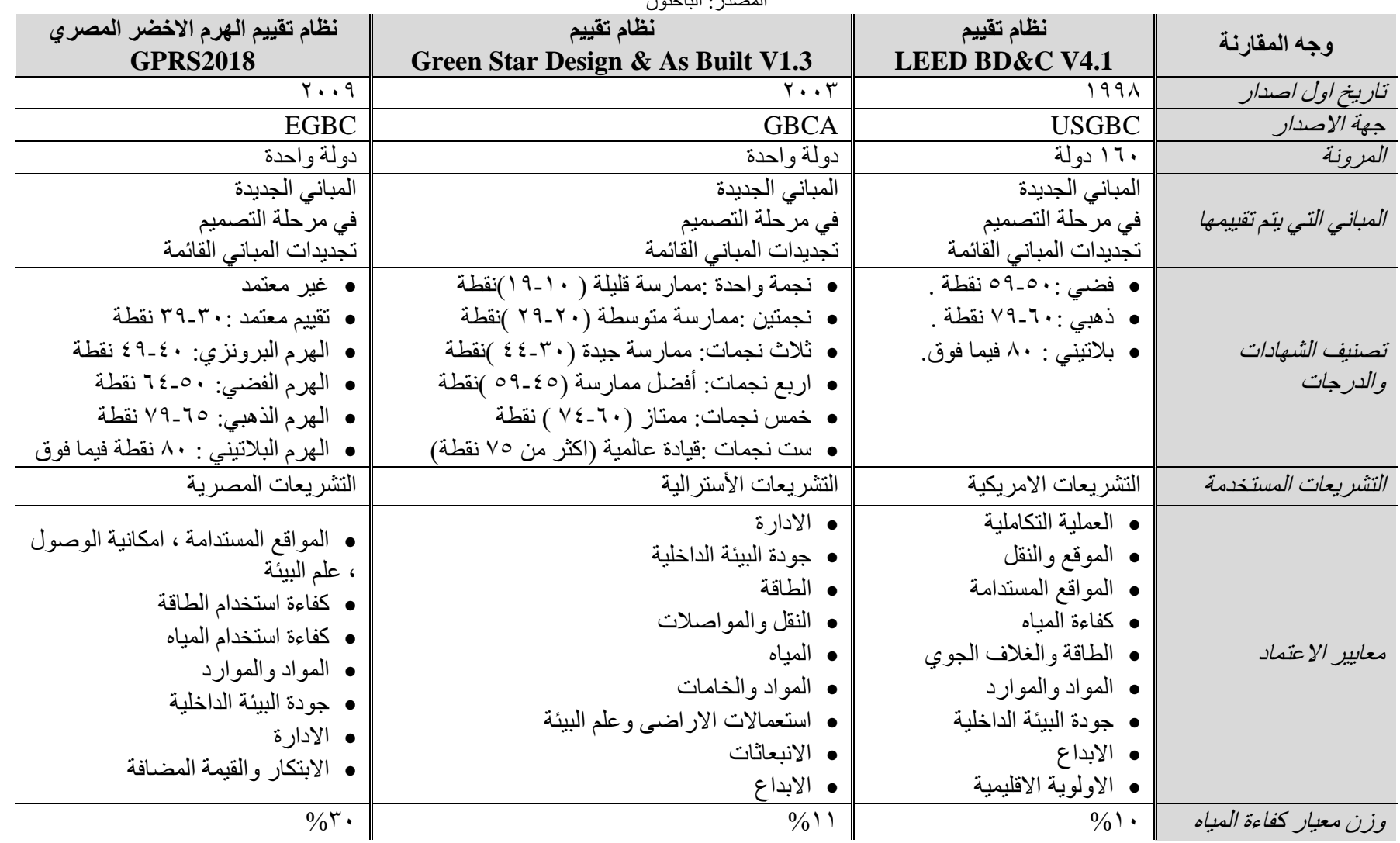

من خلال الجدول السابق يتضح أن الوزن النسبي لمعيار كفاءة المياه بنظام التقييم المحلى GPRS2018 يمثل أعلى نسبة وهذا يتضح اكثر بالمخطط رقم ( 11 ) . 


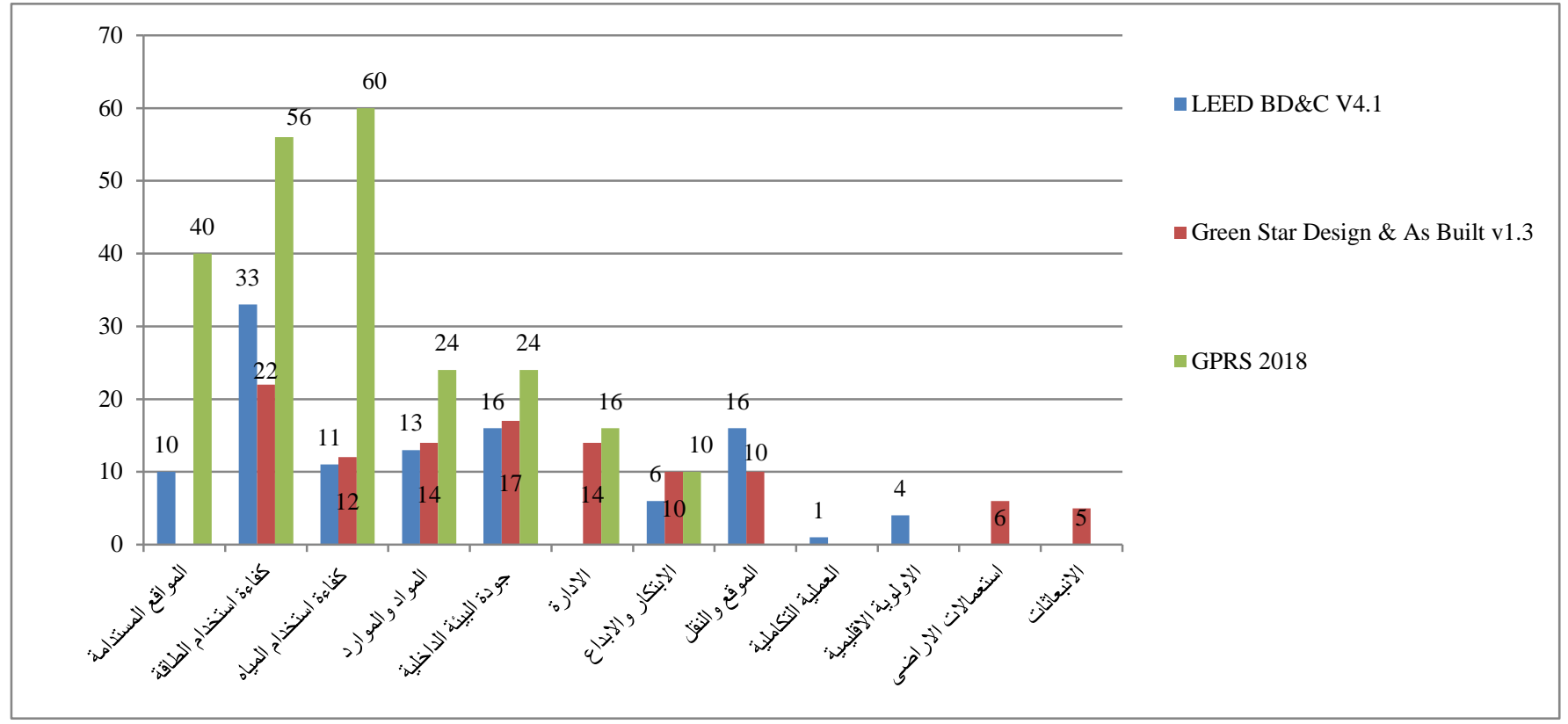

مخطط رقم ( 11 ) ) : يوضح قيم النقاط بكل معيار من معايير أنظمة التقييم الثناثة

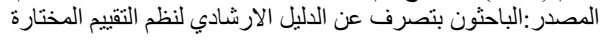

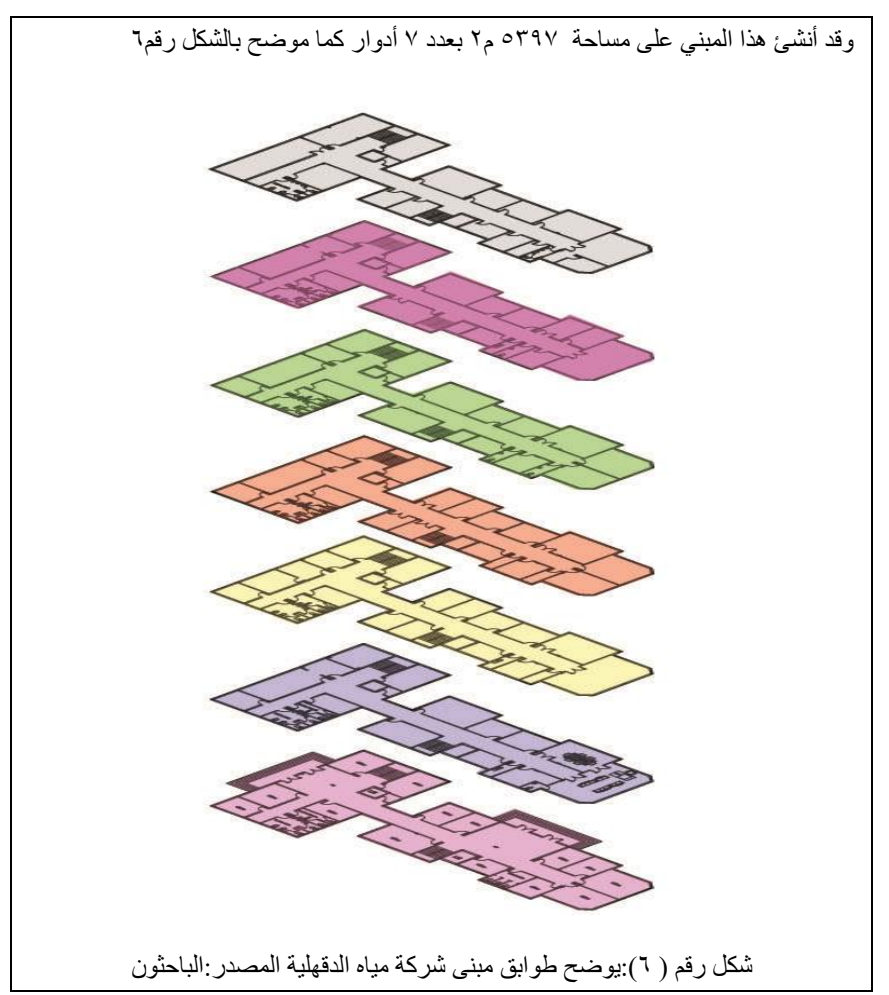

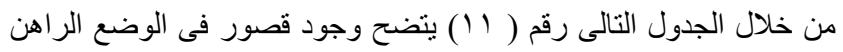

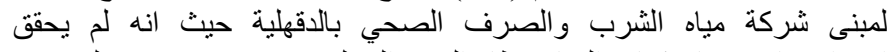

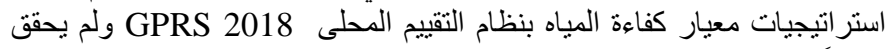
جزئباً سوى ري المناظر الطبيعية باستخدام طلمبات مياه غير المستخدمة فى المباه

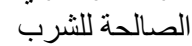
كما نستخلص من المثال التطبيقي وجود نقص في فئات معيار كفاءة المياه

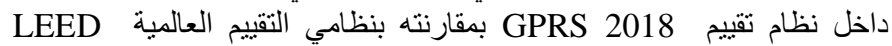
GREEN STAR Design \&As built V1.3،BD\&C V1.4 يذكر داخل معيار كفاءة المياه التالي :

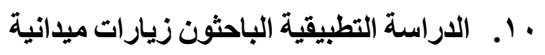

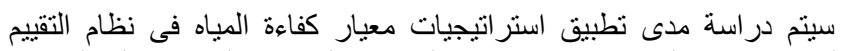

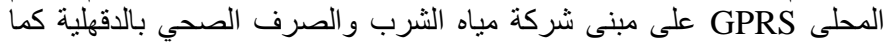
موضح بالجدول رقم (· (1)

جدول رقم (·) (1)

تقييم الوضع الر اهن لمبنى شركة المباه من خلال نظام تقيبيم GPRS2018 المصدر :الباحثون زيار اتليان ميدانية

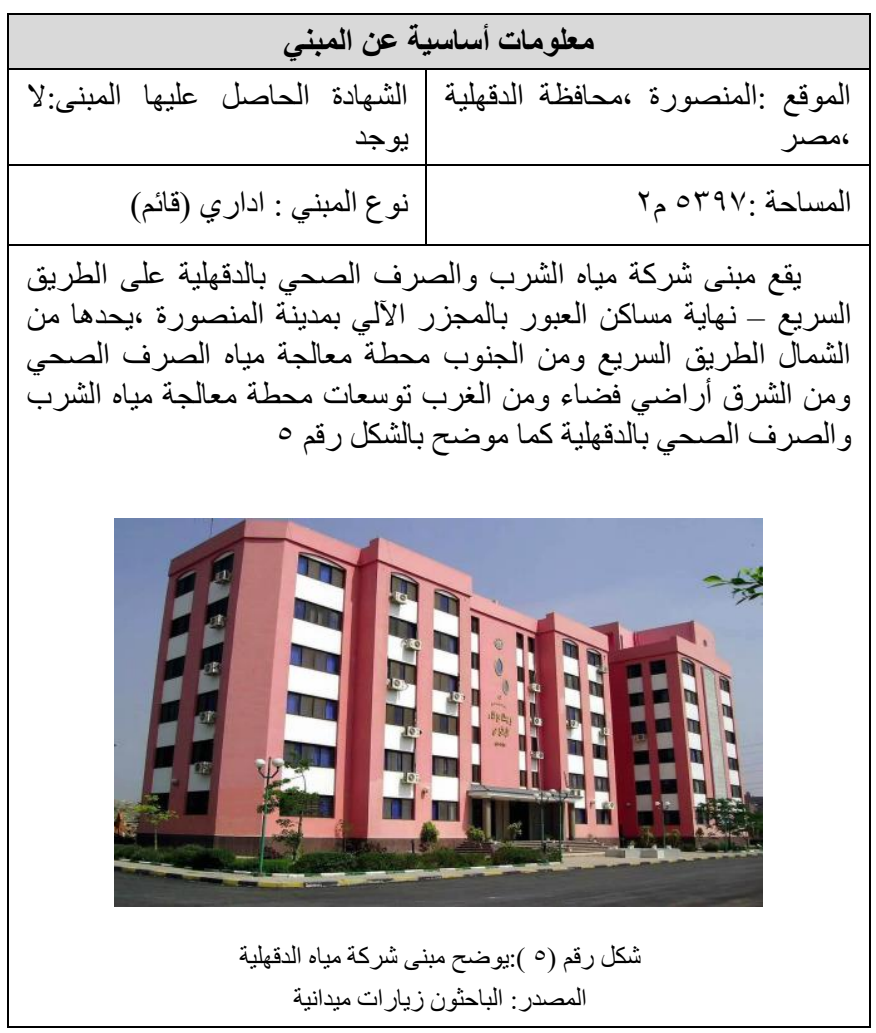




\begin{tabular}{|c|c|}
\hline 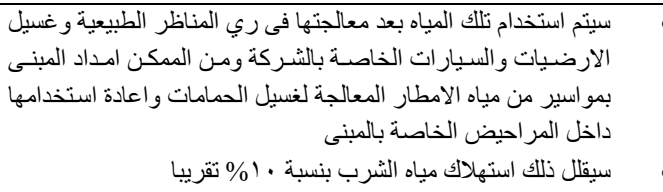 & اعبادة الاستخدام \\
\hline 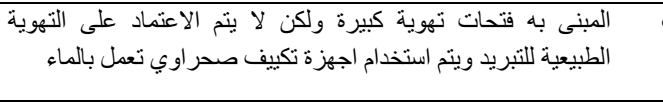 & امتصاصل \\
\hline 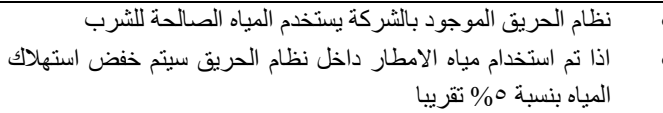 & الحتبار المياه \\
\hline
\end{tabular}

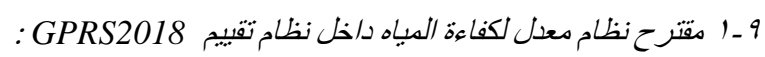

من خلال تقييم مبنى شركة مياه الدقهلية وتطبيق استر اتيجيات معيار كفاءة

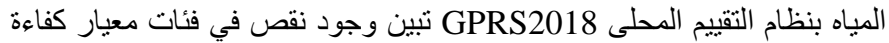

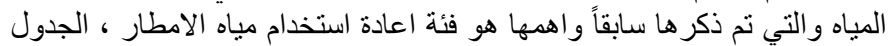

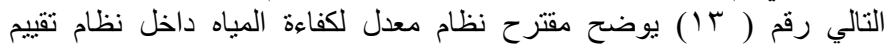

GPRS2018

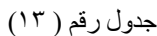

GPRS2018 مقترح نظام معدل لكفاءة المياه داخل نظام تقان تقييم

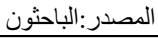

\begin{tabular}{|c|c|}
\hline النقاط & المعيار \\
\hline$r$. & اعادة /ستخدام مياه الصرف الصحى \\
\hline 1. & كفاءة /ستخد/م المباه في المناظر الطبيعية \\
\hline r. & كفاءة العباه للتتركييات الصحية \\
\hline 1. & العدادات وكثف التسرب \\
\hline 0 & اعادة /ستخد/م مباه الأمطار \\
\hline 0 & استخدام المباه للتببريد \\
\hline 0 & اختبار العباه فى نظام الحريق \\
\hline vo & الاجمالى \\
\hline
\end{tabular}

من خلال تطبيق استراتيجيات معيار كفاءة المياه داخل نظام تقييم

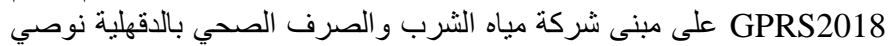

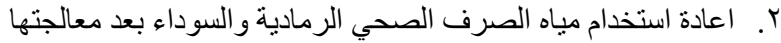

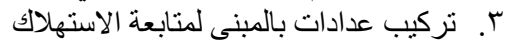

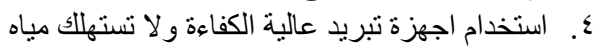

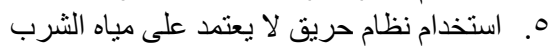

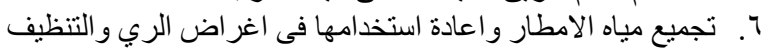

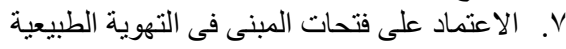

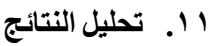

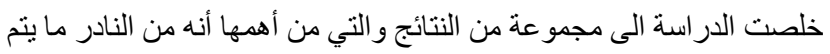

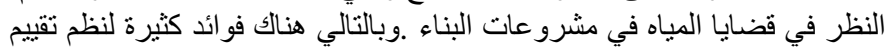

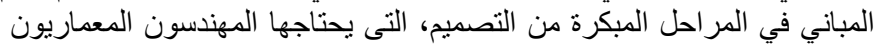

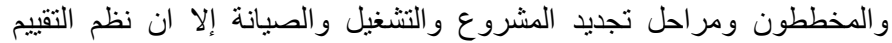

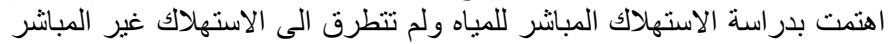

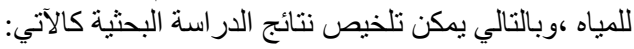

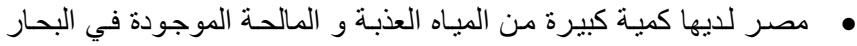

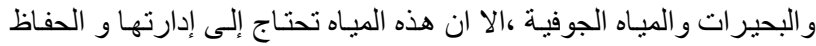
عليها .

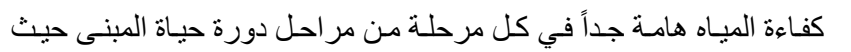
يظهر بكل مرحلة الدور المختلف للمصمم المعماري من فراهي
ا ب. أبتخدام المياه للتبريد

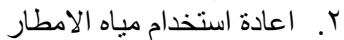

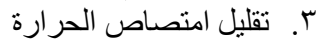

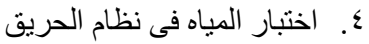

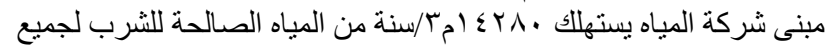

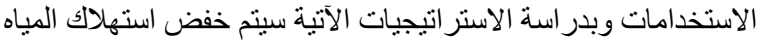

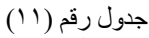

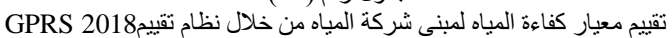

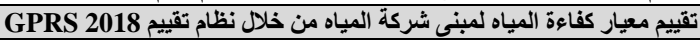

\begin{tabular}{|c|c|c|}
\hline مدى تحقق البند & الاستر اتيجيات & البند \\
\hline لم يتحقق & 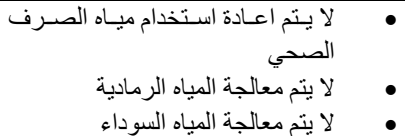 & الصرف الستخدام مياه \\
\hline تحقى جزئيا & 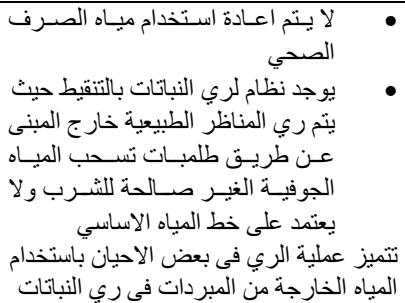 & في كفاءة استخدام المباه \\
\hline لم يتحقق & 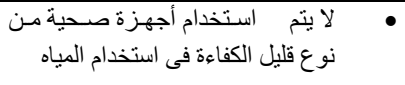 & للتركيبات الصيحية \\
\hline لم بتحقق & 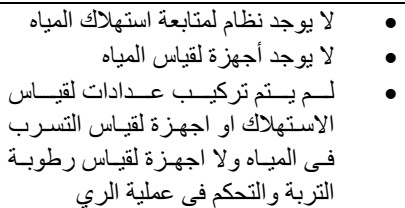 & العدادات وكثبف \\
\hline
\end{tabular}

جدول رقم ( T T ) :مدي تحقت الفئات المقترح اضافتها بنظام GPRS2018 الدصدر:الباحثون زيار اتثن ميدانية

\begin{tabular}{|c|c|}
\hline مدي تحقق البند & الفئة \\
\hline 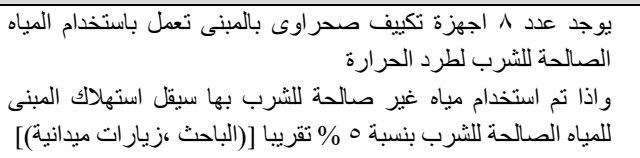 & استخدام المياه \\
\hline 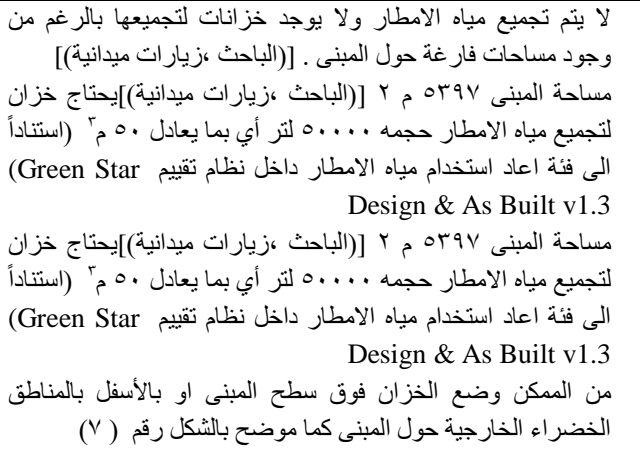 & اعياد الامطار التخدام \\
\hline ض : جع خز ابرث تجميع مباه الامطار & اعياه الامطار استخدام \\
\hline
\end{tabular}


منظومة التقييم لتشمل كل مر احل المشروع من خـلال دمـج جو انب الهندسـة المختلفة مع التصميم الداخلي. ضرورة وضع الفئات الخاصة بـ (استخدام المياه للتبريد و اعادة استخدام مياه الامطار وتقليل امتصاص الحرارة واختبار المياه في نظام الحريق) لمعيار GPRS كفاعة المياه داخل نظام 2018 مر اعاة صناعة اجزةة صحية موفرة للمياه و عالية الكفاءة مع تو افر صبانتها

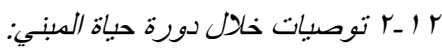
يوضح المخطط رقم r ا التوصيات الخاصة بالمصدم المعماري لودي خلادل دورة حياة

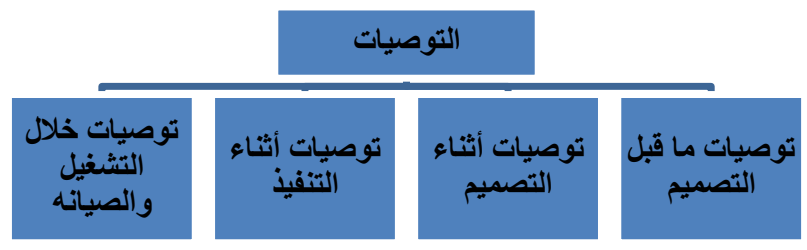

مخطط رقم (r ) ): تقسيم توصيات البحث

أ - توصبات ما قبل التصديخ:

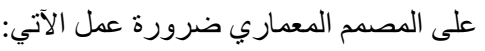

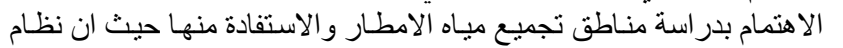
التقييم المحلى لم يتطرق لتلك النقطة داخل معيار كفاءة المياه

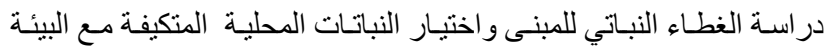

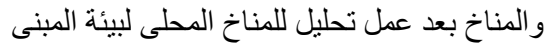

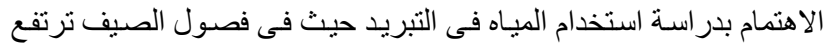

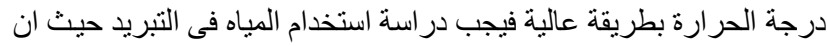
نظام التقييم المحلى لم بتطرق لتلك النقطة داخل معيار كفاءة المباه ب- توصبيات أثناء التصديم:

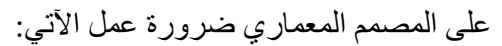

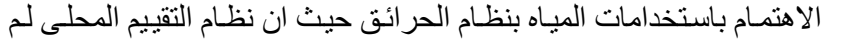
يتطرق لتلك النقطة داخل معيار كفاءة المياه

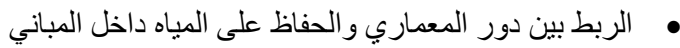

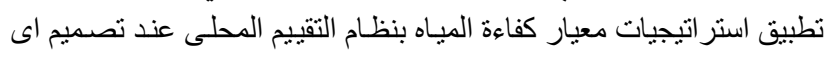

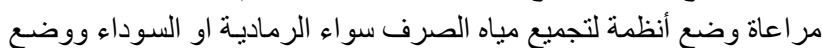

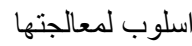
اختيار الاجهزة الصحية الموفرة للمياه • اختيار اجهزة التكييف التي لا تستخدم المياه اثناء التبريد التهوة لمياه

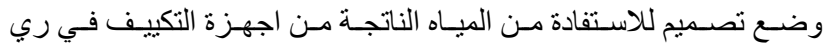

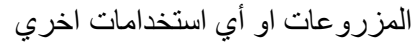

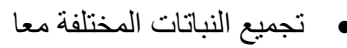

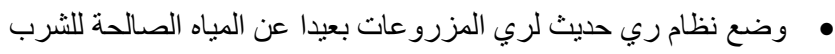
ت- توصيات أثناء مرحلة التنفيز:

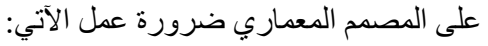

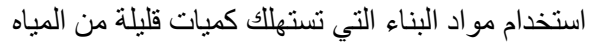
• استخدام المياه المعاد تدوبر هاد الثناء البناء تُبناء

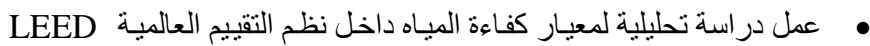
Green Star Design \& As Built V1.3 وBD\&C V4.1

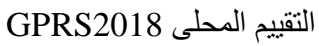

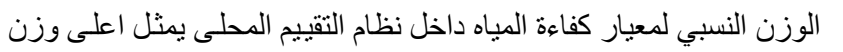

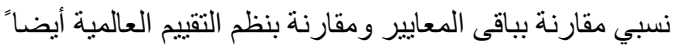

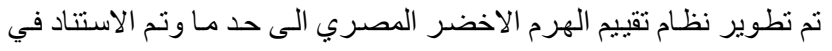

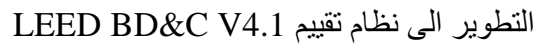

رغم تطوير النسخة الثانية من نظام تقييم GPRS2018 الا ان معيار كفاءة

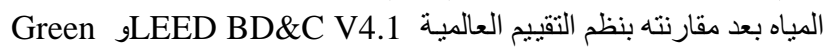
Star Design \& As Built V1.3

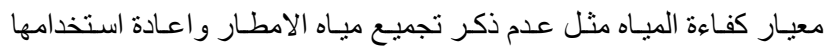

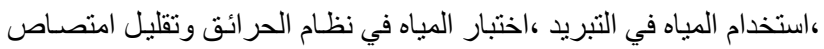

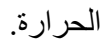

ظهر دور المهندس المعماري من خـلال الاستفادة من تحليل استر اتيجيات معيار كفاءة المياه بنظم تقييم المباني العالمية كالآتي: $\checkmark$

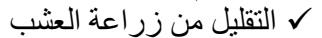
$\checkmark$

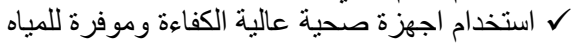

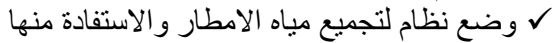

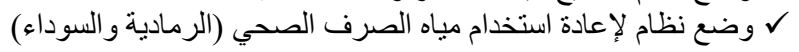

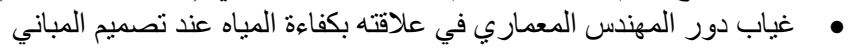

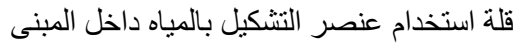

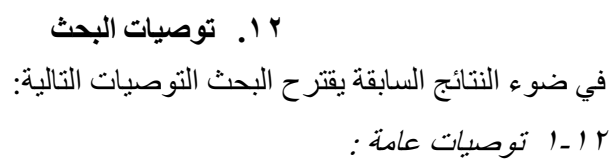

نتيجة الاهمال الجزئي لنظم تقييم المباني المحلية الفترة السـابقة يتم التوصبية

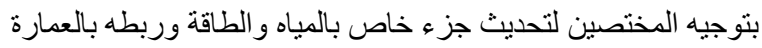

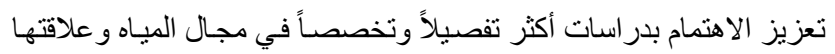

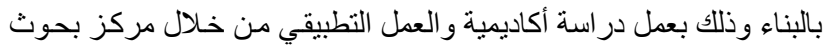

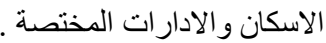

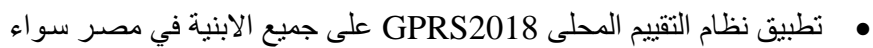
مباني جديدة او تجديدات • ضرورة توعية المجتمع بدور الاستدامة والحفاظ على المياه

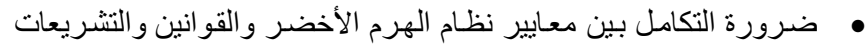
المنظمة للبناء عن طريق إدر اج مفاهيم العمارة المستدامة و التصميم الداخلي التئي

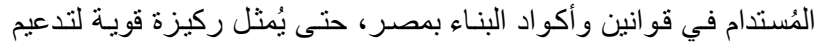

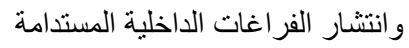

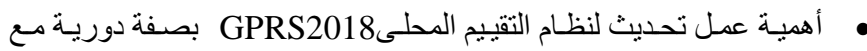

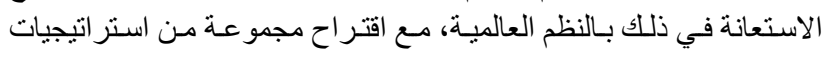

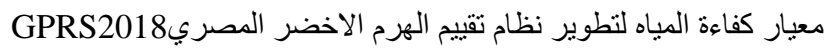
والارتقاء به

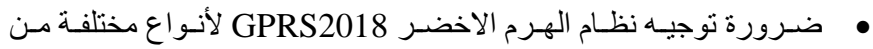
المباني(مباني جديدة ــياني قائمة ـمستشفيات ـمدارس -....الخ) مثل نظم تقييم Green Star Design \& As Built وLEDD BD\&C V4.1 V1.3 • ضرورة تفعيل وتطوير نظام تقييم الهرم الأخضر، بحيث يلعب دوراً أكثر

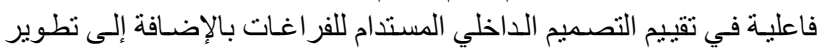


[9] Blount, S. (2018)," Home Water Use in the United States", Accessed 8/2021, from National Environmental Education Foundation : www.neefusa.org/

[10] Calkins, M. (2009)," Materials for Sustainable Sites”, volume 11 ,New Jersey, Wiley

[11] CAPMAS. (2019), Water crisis in Egypt. Accessed 8/2021, from Egyptian central agency for public mobilization and statics: www.capmas.govv.eg

[12] CAPMAS. (2020, June 13). Current population. Accessed 8/2021, from Egypt population. (2021). Accessed 8/2021, from world meters: www.capmas.govv.eg

[13] Dean, C. 2018. Energy efficiency for buildings. France:UNEP.

[14] El-Din, M. M. (2013)," Proposed climate change adaptation strategy",Cairo:

[15] Green Building Council Australia Green Star , https://new.gbca.org.au/rate/green-star, Design \& As Built v1.3

[16] Green Building Council Australia, https://new.gbca.org.au/rate/greenstar, Accessed 8/2021

[17] Groundwater usage, (2016), Accessed 8/2021, from National groundwater association: www.ngwa.org

[18] Hanna, George Bassili(2015), Chapter 54.

[19] Hazem, nahla , Abdelraouf, mohamed (2020)," A Novel Green Rating System for Existing Buildings",paper, Sustainability 2020, 12, 7143; doi:10.3390/su12177143 , Published by www.mdpi.com/journal/sustainability Egypt,p2

[20] http://www.bom.gov.au/water/waterinaustralia/, Accessed 8/2021

[21] K.GWaidyasekara, M. D. 2013. Comparative study of greenbuilding rating systems:in terms of water efficiency andconservation. Colombia: the second world constructionsymposium.

[22] Mesfin M. Mekonnen* and Arjen Y. Hoekstra (2016)," SUSTAINABILITY Four billion people facing severe water scarcity"Published Paper, Twente Water Centre, University of Twente, Drienerlolaan 5, 7522 NB Enschede, Netherlands,p3, available at http://advances.sciencemag.org/.

[23] MWRI. (2018),water povety in Egypt. Accessed 8/2021, from Ministery of water resources and irrigation: www.mwri.gov.eg

[24] MWRI. (2021), water povety in Egypt. Accessed 8/2021, from Ministery of Our Nation's Growing Water Crisis. (2019). Accessed 8/2021 from Safety management: www.afetymanagement.eku.edu

[25] Reardon, C., \& Downton, P. (n.d.) (2014) ,5th edition” technical manual, Austalla s guide to environmentally sustainable homes", 7 . Water Use, Australian Greenhouse Office,p220

[26] Srour. M, September 23(2019)," Water Scarcity and Poor Water Management Makes Life Difficult for Egyptians", IPS ,Inter Press Service New Agency. Available at: http://www.ipsnews.net/2018/09/water-scarcity-poor-watermanagement-makes-life-difficult-egyptians/.Accessed 8/2021.

[27] Stauffer, B. (2019, june 13). Rivers. Accessed 8/2021, from Sustainable sanitation and water management: $\underline{w w w . s s w m . i n f o}$

[28] The Arab Republic of Egypt Ministry of Housing, Utilities and Urban DevelopmentThe Green Pyramid Rating System In conjunction with The Egyptian Green Building Council, second Edition -2018

[29] UCOP. (2015),Construction services- UC facilities manual, USA, university of california

[30] Voutchkov, N. (2016, August 17). Desalination past, present and future.Accessed 8/2021, from International water assossiation: www.IWA.org

[31] WHO. (2011), "Safe drinking water from desalination", World health organization WHO/HSE/WSH/11.03

[32] wikipedia. (n.d.). Water efficiency Accessed 8/2021, from wikipedia: http://en.wikipedia.org/wiki/Water_efficiency

[33] William J. Warthem foundation ,(2018), On site non-potable water reuse- Practice guide

[34] World Bank. (2015). Accessed 8/2021, from our world in data:

[35] World Green Building Council (2016-2018), "Our Green Building Councils",London,UK, http://www.worldgbc.org/our-green-buildingcouncils, Accessed 8/2021

[36] World Green Building Council (2016-2018), "Our Green Building Councils",London,UK, http://www.worldgbc.org/our-green-buildingcouncils, leed V4.1 for BDC ,Credit Mapping, Accessed 8/2021

[37] World Green Building Council 2021, "Our Green Building Councils". World Green Building Council. London.UK, https://www.usgbc.org/leed, leed V4.1 for BDC ,guide, Accessed $8 / 2021$

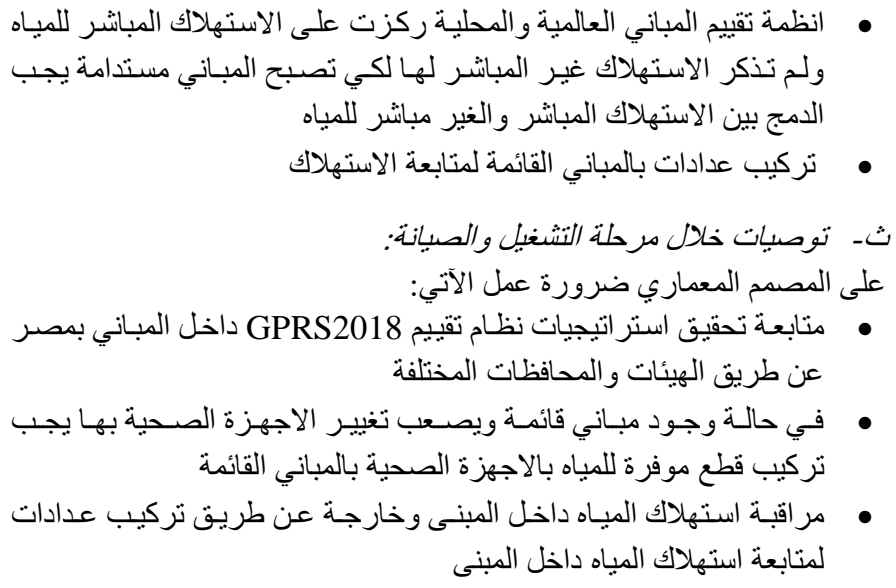

\section{Authors Contribution}

1. Conception or design of the work $(60 / 20 / 20)$

2. Data collection and tools (60/20/20)

3. Data analysis and interpretation $(60 / 20 / 20)$

4. Funding acquisition (60/20/20)

5. Investigation $(60 / 20 / 20)$

6. Methodology (60/20/20)

7. Project administration $(60 / 20 / 20)$

8. Resources (60/20/20)

9. Supervision $(20 / 40 / 40)$

10. Drafting the article $(60 / 20 / 20)$

11. Critical revision of the article (60/20/20)

12. Final approval of the version to be published (20/40/40)

The corresponding author is responsible for ensuring that the descriptions are accurate and agreed by all authors.

\section{FUNDING STATEMENT:}

The author did not receive any financial support of the research authorship and publication of this article

\section{DECLARATION OF CONFLICTING INTERESTS STATEMENT:}

The author declared that there are no potential conflicts of interest with respect to the research authorship or publication of this article

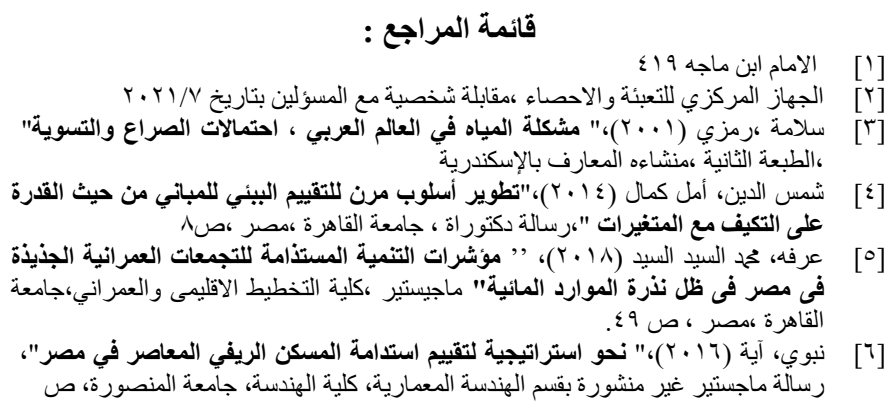

[7] Abd El-Hamid, Ahmed Khaled Mohamed (2013), "The Study of Water Efficiency for Egyptian Red Sea Resorts", Thesis Submitted, Faculty of Engineering, Ain Shams University,cairo , p63

[8] Active, beautiful, clean waters programme- certified projects. (2018),Singapore,PUB, Singapore national water agency 


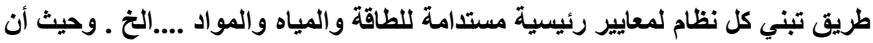

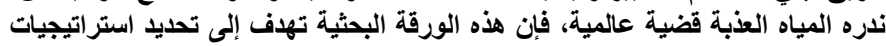

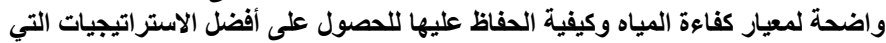

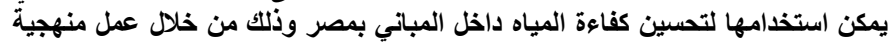

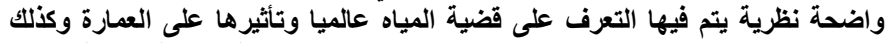

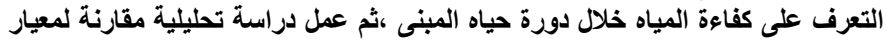
كفاءة المياه داخل نظام تقييم GPRS 2018 ولماه و، GREEN STAR V1.3 design \& as built و LEED V4.1 BD\&C اختتمت الاراسة بمثال تطبيفي لاستراتيجيات معيار كفاءة المياه بنظام التقييم المحلى

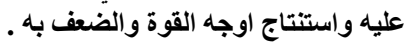

Arabic Title

دراسة تحليلية مقارنة لمعيار كفاءة المباه بنظم تقييم المباني الخضراء

\section{Abstract Arabic}

الماء العذب مورد نادر بطئ التجدد ، لذا فان ادارة المياه أمر غاية في الاهمية

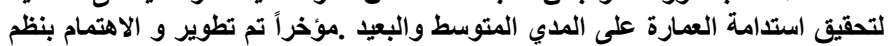

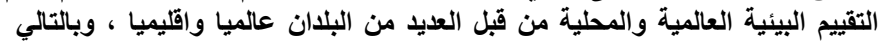

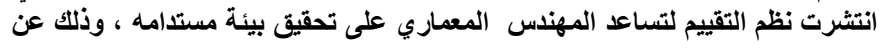

